Navon, M., Shechter, A., \& Bar-Anan, Y. (in press). The effect of group membership and individuating information on automatic and deliberate evaluation of well-known people. Journal of Personality and Social Psychology.

The Effect of Group Membership and Individuating Information on Automatic and Deliberate Evaluation of Well-Known People

\author{
Mayan Navon \\ Department of Psychology, Ben-Gurion University of the Negev, Beer-Sheva, Israel
}

Anat Shechter

Department of Psychology, Ben-Gurion University of the Negev, Beer-Sheva, Israel

Yoav Bar-Anan

School of Psychological Sciences, Tel-Aviv University, Israel

Authors' note: Correspondence should be addressed to Mayan Navon, Department of Psychology, Ben-Gurion University of the Negev, Israel. E-mail: mayanna@post.bgu.ac.il. This work was supported by the Israel Science Foundation [grant number 779/16], awarded to Y. Bar-Anan. The materials, data, and pre-registrations are accessible at https://osf.io/73gvx/. 


\begin{abstract}
People's automatic (unintentional, uncontrollable, and efficient) preference between social groups often determines their automatic preference between unknown individual members of these groups, a prominent example for automatic prejudice. What happens when the person making the judgment has long known the target individuals? Practice might automatize the deliberate judgment of the individuals. Then, if deliberate judgment is non-prejudiced, automatic prejudice might decrease. In 29 studies (total $\mathrm{N}=4,907$ ), we compared preferences between a famous member of a dominant social group and a famous member of a stigmatized social group on indirect measures of evaluation that were developed to measure automatic preference and on self-report measures. In most studies, we chose pairs based on prior self-reported preference for the member of the stigmatized group. The measures showed discrepancy, with indirect measures suggesting an automatic preference for the member of the dominant group. We replicated these results with various target individuals, two pairs of social groups (Black/White, Old/Young), two indirect measures, and in two countries (Studies 1-23). The indirectlymeasured pro-dominant preference was stronger when visual characteristics of the group were present rather than absent (Studies 24-25), suggesting a stronger effect of group characteristics on automatic than on deliberate preference between the individuals. On self-report and indirect measures, the preferences between individuals were related to the preferences between their groups (Studies 26-27), yet also to individuating information (Studies 28-29). Our results suggest that group evaluation plays a central role in the automatic evaluation of familiar (and not only novel) members of stigmatized groups.
\end{abstract}

Keywords: automatic, deliberate, individuation, stereotypes, prejudice, intergroup relations 


\section{The effect of group membership and individuating information on automatic and deliberate evaluation of well-known people}

People constantly judge other individuals (Gilbert, 1989; Jones \& Nisbett, 1987).

Because people detect the social group of others rapidly and spontaneously (Ito \& Urland, 2003, 2005; Quinn et al., 2010), and knowledge structures about groups are activated spontaneously (e.g., stereotypes and prejudice; Blair \& Banaji, 1996; Bodenhausen \& Macrae, 1998; Fazio et al., 1995; Kunda et al., 2002; Kunda \& Spencer, 2003), the judgment ${ }^{1}$ of the group might bias the judgment of the individual. This might be especially true for relatively unintentional, uncontrollable, quick, or effortless judgment (i.e., automatic judgment, as opposed to a more intentional, controllable, slow, and effortful deliberate judgment). There is some evidence that people do indeed make group-based judgments when they have no knowledge about the individual, other than the individual's group affiliation (Chen \& Ratliff, 2015; Ranganath \& Nosek, 2008; Ratliff \& Nosek, 2011).

Does social group membership bias the judgment of well-known others as well? Anyone who has ever known an individual member of a stigmatized group (e.g., an admired artist, an acquaintance) probably wondered whether, despite knowing them for a long time, he or she is still prejudiced against them, unintentionally. People often have some level of familiarity with the individuals they judge, from direct interaction or from public media. That individuating information might reduce the effect of group membership on judgment. Despite the prevalence of prior knowledge about the individuals that people judge in real life, research has yet to examine the effect of group membership on the automatic judgment of well-known individuals. In the present research, we sought to test whether, compared with deliberate (i.e., non-automatic) favorability judgment, the automatic favorability judgment of well-known individuals is biased by their social group membership. For that purpose, we compared self-

\footnotetext{
${ }^{1}$ We use judgment to refer to a response that reflects the person's estimation of the degree of any characteristic of the target, and evaluation as favorability judgment - judgment of how positive or negative the target is.
} 
reported favorability judgments with judgments inferred from indirect measures that were developed to measure automatic favorability judgment.

\section{The Measurement of Automatic Judgment}

Measures of judgment are often classified as direct or indirect, based on their structural properties (De Houwer \& Moors, 2010). Direct measures of judgment ask the participants to report their judgment, while indirect measures of judgment do not require the participant to make a judgment directly. Rather, the judgment is inferred from the participant's performance (usually reaction-time and accuracy) in different parts of the task. Many researchers have used indirect measures to examine automatic judgment of groups, individuals, and other concepts and objects (for reviews, see Gawronski \& De Houwer, 2014; Gawronski \& Hahn, 2019). A process or a response is automatic if it is characterized by one or more of the following features: it occurs unintentionally, uncontrollably, unconsciously, or with little need for cognitive resources (Bargh, 1994; Gawronski \& De Houwer, 2014; See De Houwer \& Moors, 2007, 2010, for additional possible features of automatic processes).

Because of the multi-faceted nature of the automatic judgment construct, many have recommended researchers to clarify what they mean when using this concept (Corneille \& Hütter, 2020; De Houwer, 2006; De Houwer \& Moors, 2010). Specifically, researchers were encouraged to refer to the specific automaticity feature(s) they are interested in in the context of their research (e.g., awareness, intention, efficiency, control), to facilitate conceptual clarity and advance theory and research. Corneille and Hütter (2020) further recommended to use measures that best fit the automaticity feature of interest. Yet, there are currently no wellvalidated measures that tap unintentional judgment, uncontrolled judgment, or efficient judgment separately. The existing measures were not designed to tap specific automaticity features. Therefore, when referring to the construct supposedly captured by these measures, 
there is currently no easy alternative to umbrella terms such as implicit attitudes or automatic judgment.

Of the indirect measures developed to capture automatic judgment, the Implicit Association Test (IAT; Greenwald et al., 1998) is the most common (Nosek et al., 2011). In the IAT, participants categorize items to one of four categories (e.g., Flower, Insects, Pleasant, Unpleasant). Although there are four categories, the task includes only two response options: pressing one of two keys on the computer keyboard. Two categorizations share each key. Most participants respond more easily (quickly and accurately) when the task requires participants to categorize items of the categories Flowers and Pleasant with one key and Insects and Unpleasant with the other key, than when Flowers and Unpleasant share one key, and Insects and Pleasant share the other key (Greenwald et al, 1998). A common interpretation of that finding is that in most people's memory, the concept Flowers is linked with the concept Pleasant and the concept Insects is linked with the concept Unpleasant. Therefore, participants' responding to the task should be easier when two concepts (e.g., Flowers and Pleasant) share the same response key (Gawronski \& Brannon, 2019; Gawronski \& Hahn, 2019).

We consider the IAT a potential measure of evaluation because the associations that supposedly influence performance in the IAT might influence evaluative responding in other contexts. For example, the activation of the associations with valence that influence performance in the Flowers/Insects IAT might also occur when people encounter flowers or insects in everyday life. The evaluative processes that influence the IAT score (i.e., the IAT's measurement outcome) might be less intentional and controlled than processes that influence self-reported evaluation because in the IAT, participants are not instructed to evaluate the targets, and, at least in some parts of the task, evaluation hinders performance. Further, a mental association between a target stimulus and the response has often been hypothesized to 
cause fast, efficient, unintentional, and uncontrolled response (e.g., Ach, 1935; Fazio et al., 1986; Hommel, 2000; MacLeod \& Dunbar, 1988).

In support of the hypothesis that the IAT score is related to judgment, some studies have found that manipulations that are thought to influence judgment influence the IAT score (e.g., Blair et al., 2001; Lowery et al., 2001; Mann \& Ferguson, 2015; Olson \& Fazio, 2001; Smith et al., 2013; Whitfield \& Jordan, 2009). Further, many studies have found positive correlations between people's reported attitudes and their performance in the IAT, especially on topics that do not motivate people to hide or reconsider their attitudes (Bar-Anan \& Nosek, 2014; Hofmann et al., 2005; Nosek, 2005).

There is also evidence compatible with the possibility that the processes that influence the IAT score are relatively more automatic than those that influence self-reported judgment. Faking the measurement's outcome is harder to accomplish on the IAT than on self-report (Asendorpf et al., 2002; Egloff \& Schmukle, 2002; Kim, 2003; Nosek, Smyth, et al., 2007; Steffens, 2004). Thus, it appears that the IAT scores reflect a judgment that is less intentional than a judgment captured by self-report. Some evidence suggest that the IAT also captures efficient processes, based on manipulation of cognitive effort (e.g., Devine et al., 2002; Ito et al., 2015; Schmitz et al., 2013). Some studies found that the IAT is a better predictor of behaviors performed under cognitive load than of behaviors performed without a load (e.g., Friese et al., 2008; Hofmann et al., 2007, 2008; Wiers et al., 2009), while self-report was more predictive of behaviors conducted under no load (when people can more easily control the predicted behavior). Similarly, the IAT predicted better self-regulation behaviors of people with low working-memory (WM) capacity, relatively to people with high WM capacity, while self-report showed the opposite pattern (Hofmann et al., 2008). These findings are compatible with the possibility that in the IAT scores are sensitive to relatively unintentional, uncontrolled, and efficient judgmental processes. 
Some research, however, challenged the IAT's validity as a measure of automatic judgment because it is also sensitive to non-automatic processes. Specifically, there is evidence that people are able to intentionally influence the IAT's measurement outcome (e.g., Greenwald \& Nosek, 2001; McFarland \& Crouch, 2002; Mierke \& Klauer, 2003; Steffens, 2004). Further, some have suggested that mental associations that influence the IAT measurement outcome might not always reflect judgment (Brown-Iannuzzi et al., 2019; Olson \& Fazio, 2004; Uhlmann et al., 2006). For example, an association between Black people and Unpleasant might reflect the belief that Black people suffered from unpleasant oppression, rather than a negative evaluation of Black people (Uhlmann et al., 2006).

In summary, although there is evidence that the IAT is sensitive to judgmental processes that are relatively automatic (i.e., unintentional, uncontrolled, and efficient), there is also evidence that could cast doubt on research that relies solely on the IAT as a measure of automatic judgment. To mitigate that doubt, in the present research, we used the Evaluative Priming Task (EPT; Fazio et al., 1986, 1995) as a secondary supposed measure of automatic judgment. The EPT is a sequential priming task that has been widely used as a measure of automatic evaluation (Cameron et al., 2012). It was developed to measure the "automatic activation of attitudes" (Fazio et al., 1986). In this task, participants categorize target adjective words according to their evaluative meaning (i.e., Pleasant or Unpleasant). Each adjective appears after a prime stimulus. Many have suggested that people's evaluative judgments toward the prime stimulus influences how fast and accurately they categorize the target word (e.g., Fazio et al., 1986, 1995; Gawronski \& Brannon, 2019; Gawronski \& Hahn, 2019). Namely, people categorize the words more easily when the prime and the target stimuli are congruent (rather than incongruent) in their valence.

As in the case of the IAT, the EPT might measure evaluative judgments because the priming effect seems sensitive to mental associations between the target stimuli and valence. 
There is supportive experimental (e.g., DeSteno et al., 2004; Fazio et al., 1986; Petty et al., 2006; Wittenbrink et al., 2001) and correlational (e.g., Bar-Anan \& Nosek, 2014; Cameron et al., 2012) evidence that the EPT is sensitive to judgment. Evidence suggests that it measures efficient processes, based on manipulations of cognitive load using a secondary task (e.g., Hermans et al., 2000; Klauer \& Teige-Mocigemba, 2007). For example, in a study by Hermans et al. (2000), participants completed the EPT while also performing a digits-reciting task (cognitive load manipulation). Results showed that participants' performance (i.e., reaction-times and accuracy) was unaffected by this manipulation. Additionally, evidence suggests that the priming effects in the EPT reflect relatively efficient processes because they occur very quickly: as fast as up to $100 \mathrm{~ms}$ after the presentation of the prime (e.g., Hermans et al., 2001; Klauer et al., 1997; Spruyt et al., 2007). Research has also found that the EPT is a better predictor of less controlled behaviors, relative to self-report (e.g., Dovidio et al., 1997, 2002; Spruyt et al., 2015). On the other hand, there is also evidence that the EPT can sometimes reflect non-automatic judgment (Teige-Mocigemba \& Klauer, 2008; Unkelbach \& Fiedler, 2020), and is sensitive to factors that are unrelated to judgment (see review in Unkelbach \& Fiedler, 2020).

Due to evidence that factors other than automatic judgment sometimes influence performance on the IAT and EPT, we used both measures to test our research question (as recommended by Corneille \& Hütter, 2020 and Vianello \& Bar-Anan, in press). Converging evidence from two supposed measures of automatic judgment would strengthen the confidence in the interpretation of these evidence as reflecting the construct that they were both developed to measure. In the present research, we thus used the IAT and EPT to pursue knowledge about judgments that, relatively to self-reported judgments, are more unintentional, uncontrolled, and efficient (broadly defined here as automatic judgment). Yet, it is still possible that future research might reveal that our results pertain to a currently 
unknown factor that influences the measurement outcome of the IAT and the EPT, but does not influence automatic evaluative behavior in any other context. To reduce the likelihood that our findings would be interpreted as definite evidence about automatic judgment, we describe our findings at the operational level (i.e., effects on IAT scores, EPT scores, and selfreported evaluation), and emphasize that the interpretation of our results depends on the validity of the measures we used.

\section{Automatic Judgment of Individual Group Members}

Past research has used indirect measures (mainly the IAT and EPT) to learn about the automatic judgment of social groups and of individuals. That research is limited by the same uncertainties noted in the previous section. Much research used indirect measures to learn about automatic judgments of different social groups (e.g., Devine, 1989; Devine et al., 2002; Dovidio et al., 1997; Fazio et al., 1995; Greenwald et al., 1998; Kurdi et al., 2019; Nosek, 2005; Nosek et al., 2002; Phelps et al., 2000). Most of that research found evidence that were considered as suggesting automatic preference for the ingroup or the dominant group over outgroups and non-dominant, stigmatized groups (e.g., Bar-Anan et al., 2009; Dasgupta et al., 2000; Greenwald et al., 1998, 1998; Nosek, 2005; Nosek, Smyth, et al., 2007; Ottaway et al., 2001). Importantly, such preference was found even when there was no self-reported preference for the ingroup or the dominant group (e.g., Devine, 1989; Devine et al., 1991; Payne, 2001; Plant \& Devine, 1998).

While ample research investigated the deliberate and automatic judgment of social groups, research on the deliberate and automatic judgment of individual members of social group is scarce. Impression formation models (e.g., Brewer, 1988; Fiske \& Neuberg, 1990) distinguish between two knowledge sources that influence the judgment of individuals: knowledge about the group, and knowledge about the individual. The judgment of individuals may vary by its reliance on group membership relatively to individuating information. 
Knowledge based on group-membership is a schematic impression that fits all members of that group. This type of knowledge links a certain trait or evaluative concept to all members of the group. In contrast, when people rely on individuating information as a source of knowledge about the individual, they consider the various traits, attributes, and actions that characterize that specific individual and differentiate him/her from other individuals. Theory further suggests that group-based impressions (that is, impressions that rely on groupmembership knowledge) are more automatic, in the sense that they are less resourcesconsuming (i.e., efficient) and more rapid, due to their schematic structure, while individuating impressions are more effortful (Amodio \& Mendoza, 2010; Brewer, 1988; Brewer \& Feinstein, 1999; Fiske \& Neuberg, 1990; Payne, 2005). For that reason, reliance on group-based knowledge is considered the default route, and deviating from that route requires relatively more resources (for a review, see Bodenhausen et al., 2012).

Another possible reason why group-membership influences automatic judgments of individual members of the group is that the valence of the group is activated automatically upon exposure to the individual's face. Theory suggests that, over time, certain facial features and configurations may acquire valence based on repeated pairing with the evaluation of the face's social group (Livingston \& Brewer, 2002). The result of these pairings is an automatic activation of valence in response to those facial features and configurations, independently of other sources of evaluative information. Thus, the presence of certain facial features may directly trigger valence activation independently from the target face's categorization to a social group (e.g., Black people) and from the identification of the face (e.g., as Will Smith). Accordingly, automatic prejudice towards an individual may result from multiple causes: the activation of group-based knowledge following group-categorization, the activation of valence by facial-features that are prototypical of the group, or some combination of both causes. 
Empirical research about the automatic and deliberate judgment of individual group members focused on the source of information that people rely on when individuating knowledge is not available. That research found that when individuating information is ambiguous or absent, group membership determines the outcomes of both indirect measures of judgment and self-reported judgment of individual group members (Cao \& Banaji, 2016; Castelli et al., 2004; Kunda \& Sherman-Williams, 1993; Ranganath \& Nosek, 2008).

A handful of studies tested judgment of individual targets when both groupmembership and diagnostic individuating information are available (Cao \& Banaji, 2016; Rubinstein et al., 2018). These studies used novel fictitious targets (unknown to the participant prior to the study) who belong to an existing social group. In the lab, participants read diagnostic individuating information about the targets. In one set of studies (Rubinstein et al., 2018), participants judged the intelligence of a Black person and a White person, after reading that they are both equally intelligent, a trait that is stereotypically attributed to White people more than to Black people. In another set of studies (Cao \& Banaji, 2016), participants associated an occupation with a man and a woman after reading about their counterstereotypical occupations (e.g., the man was a nurse and the woman a doctor). These studies found that diagnostic individuating information eliminated the effect of group membership on self-reported judgment. In contrast, group membership still determined the outcomes of indirect measures of judgment, despite individuating information, although the advantage of the group membership, relatively to the individuating information, varied between studies, and was smaller, the more diagnostic the individuating information was (that is, the more this information could serve as a basis to distinguish the target from other members of the group).

In summary, the evidence thus far suggests strong reliance on group-membership in indirect measures and self-report measures of judgment of individual group members, when there is no individuating information about the target individuals. When individuating 
information about the individual targets is available, initial evidence suggests that the individuating information governs self-reported judgment, whereas group-membership still governs the measurement outcomes of indirect measures of judgment, although to a very small extent when the individuating information is highly diagnostic.

\section{The Automatic Evaluation of Well-Known Individual Group Members}

We conducted the present research to learn more about the effects of individuating information and group membership on automatic judgment, in comparison to their effect on deliberate judgment. The present research has a number of novel aspects. First, previous research tested whether individuating information reduces the effect of group information on specific trait or occupation judgments (stereotypes), whereas we focused on general favorability judgment (prejudice). Stereotypes and prejudice are recognized widely across the literature as distinct constructs (e.g., Allport, 1954; Devine, 1989; Fiske, 1998; Mackie \& Smith, 1998), are sometimes only weakly (Amodio \& Devine, 2006) or modestly (VolpertEsmond et al., 2019) related, and might rely on different, independent, memory systems (affective vs. conceptual, Amodio, 2019; Amodio \& Devine, 2006). Further, trait judgments (stereotypes) and favorability judgment (prejudice) predict different forms of bias (Amodio \& Devine, 2006).

Another crucial difference between previous research and the present research is that no previous research has tested whether long held knowledge of individuating information eliminates the effect of the target's group membership on automatic judgment. The present research question pertains to individuals that the perceiver has known for quite some time. Long history of exposure to individuating information about a group member might strengthen the effect of individuating information on the deliberate and automatic judgment of that person, on the expense of the effect of the group membership. In other words, as the target person becomes more known, the perceiver no longer needs to rely on group 
membership for making the judgment. As a result, deliberate and automatic judgment might converge, with both forms of evaluation relying mostly on the individuating information.

Another reason why long history of exposure to a target individual might increase the similarity of automatic judgment to deliberate judgment is practice in the deliberate judgment of the individual. Theories of knowledge acquisition (e.g., Fazio, 2007; Fazio et al., 1982; Logan, 1988; Powell \& Fazio, 1984) suggest that experience with knowledge (via practice or repetition) leads to automatization of that knowledge. For example, according to Instance Theory (Logan, 1988), people perform novel tasks using a general algorithm, but as they accrue experience through practice, people start to retrieve the solution from memory instead of using an algorithm. Eventually, the behavior relies only on memory.

The application of Instance Theory to the case of judgment suggests that people might initially invest substantial effort when deliberately judging a specific individual. Repeated elaboration of that judgment on different instances of encountering that individual increases the likelihood that people would retrieve the deliberate judgment from memory, quickly, and effortlessly (see also Nosek, 2005, 2007; Nosek \& Banaji, 2002). Indeed, it has been shown that repeated judgment leads to faster self-reported judgment (Powell \& Fazio, 1984; Smith \& Lerner, 1986). Repeated practice in self-reported judgment also increased the likelihood that the judgment would be activated unintentionally, as measured with the EPT (Fazio et al., 1986). In other words, there is evidence that with practice, self-reported judgment becomes the evaluative response that people produce under conditions of automaticity. At that point, the automatic judgment becomes quite similar to the deliberate judgment. This line of reasoning leads to the hypothesis that the automatic judgment of well-known individual members of stigmatized groups would be similar to the deliberate judgment of these members. In that case, if deliberate evaluation does not show prejudice against well-known 
individual members of the stigmatized group, automatic evaluation might similarly show no bias.

Is there any theoretical basis for the rival hypothesis, namely, that people would show automatic prejudice toward well-known individuals? First, perhaps deliberate evaluation becomes automatized relatively easily only when people do not hold, a-priori, a strong opposite automatic evaluation. Evidence that practice automatizes deliberate evaluation (Fazio et al., 1986; Powell \& Fazio, 1984; Smith \& Lerner, 1986) comes from research on the evaluation of objects that, prior to practice, did not produce on indirect measures an evaluation that was opposite of the self-reported evaluation. In contrast, in the judgment of a novel individual member of a stigmatized group, indirect measures often suggest a negative evaluation (Chen \& Ratliff, 2015; Ranganath \& Nosek, 2008; Ratliff \& Nosek, 2011; Rubinstein et al., 2018). With repeated exposure, as the novel individual becomes wellknown, an automatization of the self-reported positive evaluation of that individual must overcome the initial (group-based) negative evaluation seen on the indirect measures. It is possible that practice of deliberate evaluation does not override the automatic activation of negative judgment, as suggested by research on treatments to reduce automatic bias in the evaluation of social groups (Forscher et al., 2019; Lai et al., 2013, 2014). Moreover, currently, there is no sufficient evidence that treatments against automatic group bias, including treatments that involve practice in non-biased judgment, have any long-lasting effects (Lai et al., 2016).

In the case of judgment of an individual member of a stigmatized group, the automatic evaluation might include reactions to (at least) two features: the specific individual and the individual's group. Despite repeated deliberate positive evaluation of the individual, the individual's group membership might continue to automatically activate prejudiced evaluation. That seems especially likely based on the finding that people's direct reaction to 
specific features of the group, such as skin color, is often based on the evaluation of group (Livingston \& Brewer, 2002). With each instance of deliberate evaluation of the individual, the automatic activation of the group evaluation would also occur. In other words, repeated encounters and judgments of the individual might provide practice for both the deliberate processes that lead to a non-prejudiced evaluation and the automatic processes that activate the prejudiced evaluation. As a result, long familiarity with the target individual might fail to eradicate automatic prejudice against that individual.

Another reason to hypothesize that long familiarity with the individual member of a stigmatized group would not eliminate automatic prejudice is the possibility that deliberate evaluation is also biased. Perhaps previous research often failed to find evidence for deliberate prejudice only because people prefer to present themselves as unprejudiced. In that case, repeated encounters and private (as opposed to publicly reported) deliberate judgments of the individual group member would provide practice of prejudiced rather than nonprejudiced deliberate judgment. As a result, automatic judgment of known individuals would remain prejudiced.

In summary, no prior research has tested the effect of group membership and individuating information on the automatic and deliberate evaluation of well-known individual members of social groups. Yet, that kind of evaluation is a frequent event in everyday life. Theoretically, the evaluation of well-known individual members of a stigmatized group is informative because it goes beyond the test of evaluations that rely on recently encoded information about novel fictitious individuals that the participant had met for the first time, a few minutes ago. Evaluation that is based on information that was encoded over a long period of time might have different effects than information encoded very recently. For example, with time and practice, the deliberate non-prejudiced evaluation might undergo automatization, leading to a non-prejudiced automatic evaluation. The opposite 
hypothesis - an automatic prejudice of well-known individual members of social groups - is not implausible because repeated deliberate non-prejudiced evaluation might not undergo automatization when an automatic prejudiced evaluation also repeats. Further, perhaps the non-prejudiced deliberate evaluation found in research about novel individual members of known groups was only a façade reported to researchers, masking an actual deliberate prejudiced evaluation. In that case, there is no non-prejudiced judgment to undergo automatization over time. To test which of the rival hypotheses is closer to the truth-and to add practical knowledge about automatic prejudice in a type of judgment that is common in everyday life - we examined whether people show automatic prejudice toward well-known members of social groups.

\section{The Present Research}

The empirical test of our research question was inspired by potentially pertinent evidence that we found in a study that examined the relation between self-reported evaluation and IAT scores across 57 pairs of objects (Nosek, 2005). One of the 57 pairs was Denzel Washington and Tom Cruise. The participants' IAT scores suggested a preference for the White actor (Cruise) over the Black actor (Washington), despite self-reported preference for the Black actor over the White actor. Nosek did not discuss this discrepancy between IAT scores and self-reported evaluation. But, perhaps the reason for that discrepancy was that group-based information dominates the automatic evaluation of individual group members even when they are known for a long time. To investigate that possibility, in the present research we replicated and extended Nosek's (2005) serendipitous finding.

We examined the effect of individuating information and group-membership on indirect measures of evaluation of well-known individual members of social groups: Popular American movie actors and musicians. The groups were Black and White people in most studies, and old and young people in Studies 21, 23, and 29. Thus, participants had much 
individuating information (e.g., from movies and from the press) and group-based information (about the race and age groups) that was not provided immediately before the evaluation measurement.

Selecting famous individuals from existing social groups as targets increases the ecological validity of the research. The targets are real people from real social groups that our participants have known for some time. However, we lacked full control of the exact individuating information each participant received about the targets. In all likelihood, over time, people were exposed to some idiosyncratic information about each target individual, but we did not know what that information was, nor its amount (see Quinn et al., 2009, for a similar reasoning). To overcome this limitation and increase our ability to make inference from the results, we usually chose target individuals who were likely to elicit self-reported preference in favor of the member of the stigmatized group over the member of the dominant group. Because in all our studies, people did not report preference for the stigmatized group over the dominant group, we could safely assume that the reported preference for the member of the stigmatized group was the result of more favorable individuating information about the member of the stigmatized group than about the member of the dominant group. Therefore, if the indirect measures would not demonstrate a preference for the member of the stigmatized group over the member of the dominant group, that would suggest that group membership (i.e., prejudice) caused that discrepancy. In contrast, if the outcomes of the indirect measures would suggest preference for the member of the stigmatized group over the member of the dominant group, that would be compatible with the possibility that individuating information determined the automatic preference between the individuals, just as it determined deliberate preference. That result would support the hypothesis that the automatic preference between well-known individual targets is not more prejudiced than deliberate preference. 
To illustrate further the logic behind the present research, let us use Study 2 of the present research as an example. In Study 2, we measured the preference between Ben Affleck (a well-known White person) and Eddie Murphy (a well-known Black person) with a selfreport questionnaire and the IAT. Participants' self-reported evaluation was compatible with an external pre-test: They reported favoring Murphy over Affleck. Because these participants reported no preference between Black people and White people, group membership is not a likely reason for the deliberate preference for Murphy over Affleck. In contrast, the participants' prior knowledge about these two actors (i.e., individuating information) is a likely reason for that preference. In other words, individuating information determined the deliberate preference between Murphy and Affleck. Now, consider the meaning of finding IAT scores that suggest a pro-Murphy preference. That would be compatible with the hypothesis that automatic evaluation is in line with (i.e., not more prejudiced than) the deliberate evaluation. What could be the reason for IAT scores that would suggest a proAffleck preference? Individuating information would not be a likely cause for that preference because we already know that the individuating information led to a pro-Murphy self-reported preference. In contrast, group membership would be a likely cause of an IAT score that suggests a pro-Affleck preference. Therefore, a pro-Affleck preference in the IAT would suggest that group membership biased the automatic evaluation, and that this effect of group membership was more pro-dominant (that is, more biased in favor of the actor from the dominant group) than the effect of group membership on deliberate evaluation.

To increase the likelihood that group membership would be the cause for any discrepancy that we find between self-reported preferences and preferences inferred from the IAT and the EPT, we replicated the study across different pairs of targets. That generalization eliminated alternative reasons for discrepancy that were idiosyncratic to a specific pair of targets. In Studies 1-17, we tested our research question with different (Black and White) 
actors using the IAT. In Studies 18-23, we tested whether our findings generalize to the EPT, to another (non-American) population, and to another social group (age: Old/Young target individuals).

In Studies 1-23, the scores of the IAT and EPT suggested a preference for the member of the dominant group over the member of the stigmatized group, despite an opposite selfreported preference. In those studies, the target individuals were always presented visually (i.e., in photos). In Studies 24-25, we tested whether the results reflected a reaction to the target individuals or to their visual group-related features. We manipulated the presentation of the target individuals: one group of participants saw only the names of the targets, whereas the other group saw the targets' photos (as in the previous studies). We tested whether the IAT scores would suggest a preference for the member of the dominant group over the member of the stigmatized group even when the visual characteristics of the targets' racial groups are not seen, and whether exposure to that characteristic would moderate self-reported judgments and IAT scores.

We assumed that the scores of the IAT and the EPT in Studies 1-25 suggested a preference for individual members of the dominant group over individual members of a stigmatized group because of an automatic preference for the dominant group. This assumption was based on previous research that found preference for the dominant group on various indirect measures (e.g., Bar-Anan \& Nosek, 2014; Nosek, 2005; Nosek, Smyth, et al., 2007). In Studies 26-27, we tested that assumption by measuring the relation between individual differences in the scores of an IAT and self-report questionnaires that measured preference between the target individuals, and individual differences in the scores of an IAT and self-report questionnaires that measured the preference between the social groups of these targets. 
In Studies 1-27, we selected the target pairs based on prior information that increased the likelihood that the member of the dominant group would not be favored over the member of the stigmatized group. Yet, in most of these studies, the result on the indirect measure suggested a preference for the member of the dominant group over the member of the stigmatized group. This result is compatible with the possibility that automatic evaluation was not sensitive at all to the individuating information. Therefore, to test the effect of individuating information on automatic evaluation, in Studies 28-29, we manipulated between participants the group membership of the preferred individual. An effect of that manipulation on the IAT and EPT scores would suggest that automatic evaluation is sensitive to individuating information, and not only to the targets' group membership.

\section{Studies 1-17: Deliberate and Automatic Evaluation of White and Black Actors}

In Studies 1-17, we used a self-report questionnaire and the IAT to measure the deliberate and automatic evaluation of famous White and Black actors. Study 1 used the same actors as in Nosek (2005). In Studies 2-17, we attempted to generalize the finding with other stimuli, to examine whether the reason for the finding was the actors' racial groups.

\section{Methods}

We report all data exclusions, manipulations, and measures, and how we determined our sample sizes. The decision to stop collecting data did not depend on the obtained results. The materials, data, and pre-registrations are accessible at https://osf.io/73gvx/?.

\section{Participants}

Participants in all studies, except Studies 20-23 and 26-27, were volunteers at the Project Implicit website (implicit.harvard.edu; Nosek, 2005). In all studies, we planned to recruit enough participants to achieve at least $80 \%$ power for an effect size of a reasonable size in social psychology (Cohen's $d=0.25$, Pearson $r=.25, \eta_{p}^{2}=.02$ ). The pre-registration files provide further details about our power calculations for each study. For each study in this 
research, Table 1 presents the number of participants who (1) started each study, (2) completed the study, (3) were excluded from the study, (4) were included in the analyses (along with their demographic information). In all studies, we excluded participants who had $>10 \%$ fast trials in the IAT (RT<300 ms; see Greenwald et al., 2003). All studies were approved by the ethics committee of the Psychology department at ***[MASKED for the review] University.

\section{Stimuli}

In Study 1, we used Tom Cruise and Denzel Washington. In Studies 2-17, we used all 16 combinations of four White actors (Clint Eastwood, Johnny Depp, Ben Affleck, and George Clooney) and four Black actors (Will Smith, Samuel L. Jackson, Morgan Freeman, and Eddie Murphy). The actors were chosen based on popularity ratings on a website that presented popularity surveys (today.yougov.com). We chose Black actors who were moderately more popular than the White actors (For popularity ratings see Table S1 in the online Supplement Materials). That selection was successful, as confirmed by the selfreported preference reported below, favoring the Black actor in all the studies. We attempted to obtain only moderate preference for the Black actor, in order to increase the likelihood of finding a significant preference for the White actor on the indirect measure despite a selfreported preference for the Black actor. Such opposing preferences are relatively invulnerable to alternative accounts for that discrepancy, based on lower reliability of the indirect measure, in comparison to the self-report measure. Consider, for example, the finding of a strong selfreported preference for the Black actor over the White actor and only a weak preference for the Black actor over the White actor on the indirect measures. That finding might reflect a stronger effect of the actor's group membership on automatic than on deliberate evaluation. However, it could also reflect a weaker sensitivity of the indirect measure to attitudes due to lower reliability. Such an alternative account, however, cannot explain the finding of a 
significant self-reported preference for the Black actor and a significant preference for the White actor on the indirect measures.

\section{Procedure}

Participants completed a self-reported evaluation questionnaire and the IAT, in a random order. Because the IAT might reflect a combination of the evaluations of the stimuli and the category labels (Gawronski, 2019), the self-report measure in Studies 2-17 also included ratings of the IAT stimuli - the photos of the actors. Studies 2-17 also included a self-report measure of the social groups (White people and Black people), administered after the measures of the actors' evaluation.

\section{Measures}

Implicit Association Test (IAT; Greenwald et al., 1998). The categories in the IAT were the full names of the actors (e.g., Ben Affleck and Eddie Murphy), and their stimuli were five photos of each actor (all photos were obtained using a Google search for photos labeled as free for reuse). The labels of the attribute categories were Good words (stimuli: positive, pleasant, good, outstanding, beautiful, magnificent, marvelous, excellent, appealing, delightful) and Bad words (stimuli: negative, bad, horrible, miserable, hideous, dreadful, painful, repulsive, awful, ugly). The IAT consisted of the standard seven blocks design (Nosek, Greenwald, et al., 2007), with a random assignment of the first pairing condition in the task (i.e., whether the White actor shared a key with Good words or with Bad words). We used the IAT D score (the D600 algorithm, Greenwald et al., 2003), with scores above zero indicating a preference of the White actor over the Black actor (i.e., faster responses when the White actor shared a key with Good words, and the Black actor shared a key with Bad words than when the key assignment was the opposite).

Self-Reported Evaluations. Participants answered the question How cold or warm do you feel toward Eddie Murphy [for each of the two actors]? with a visual analog scale that 
ranged from 0 (very cold) to 100 (very warm) (adapted from Nosek, 2005). The order of the two questions (White actor, Black actor) was counterbalanced between participants. For each actor, participants also responded to three questions in the format of How likable [trustworthy, friendly] is Eddie Murphy? Using response options that ranged from 1 (Extremely unlikeable [untrustworthy; unfriendly]) to 9 (Extremely likeable [trustworthy; friendly]) (adapted from Moran et al., 2017). The order of the six questions (three for each actor) was randomized for each participant. The self-reported evaluation score was the average response to the four questions (after rescaling the three questions to match the feeling thermometer response scale). The difference between the evaluation scores of the two actors was the self-reported preference score.

Photo Evaluation. For each of the ten photos used in the IAT as stimuli for the actors, the participants answered the question How negative or positive are your feelings when seeing this photo? With the response options Extremely negative, Moderately negative, Slightly negative, Neutral, Slightly positive, Moderately positive, Extremely positive, coded 1 to 7 , respectively. The average of the responses for each actor was the photo evaluation score and the difference between the two evaluation scores was the photo preference score.

Race Evaluations. Participants answered three questions in the format of On average, who do you think is more likable [trustworthy; friendly], Black people or White people? with response options that ranged from 1 (Black people are extremely more likable [trustworthy; friendly] than White people) to 7 (White people are extremely more likable [trustworthy; friendly] than Black people). A fourth question was Please indicate your preference between Black people and white people with response options that ranged from 1 (I strongly prefer Black people over White People) to 7 (I strongly prefer White people over Black People). These four items were averaged into a single score of self-reported preference for White people over Black people. 


\section{Results}

Figure 1 presents all the effect sizes and a meta-analysis of all the studies. Table 2 presents the descriptive statistics and reliability for the preference between the actors in each study.

\section{Self-Reported Evaluation}

In all 17 studies, participants evaluated the Black actor more positively than the White actor. Cohen's $d$ s for the difference between the two evaluations ranged from -0.17 to -1.05 (negative scores indicate a more positive evaluation of the Black actor). We conducted a meta-analysis of all studies with a random-effects model, to estimate the effect-size across the different studies. That meta-analysis found an effect of $d=-0.63[-0.77 ;-0.49]$ that was significantly different from zero, $z=-8.99, p<.0001$. For both the current analysis and the photo evaluation analysis, Cohen's $d$ was calculated using $S_{\text {pooled }}$ (recommended by Lakens, 2013). The calculation of $S_{\text {diff }}$ (recommended by Borenstein et al., 2009) resulted in an identical meta-analytic effect (and similar confidence-intervals). These results confirm that we successfully chose pairs of people who elicited self-reported preference for the member of the stigmatized group over the member of the dominant group.

\section{Photo Evaluation}

In 15 of the studies, the mean evaluation of the photos of the Black actors was more positive than the evaluation of the photos of the White actors' (Cohen's $d$ s ranged from -1.64 to 0.23 ). A meta-analysis of all studies with a random-effects model yielded an effect of $d=$ $-0.78[-1.01 ;-0.54]$ that was significantly different from zero $z=-6.44, p<.0001$. 
Table 1

Studies 1-29: Details about the participants

\begin{tabular}{|c|c|c|c|c|c|c|c|c|}
\hline Study & Target Pair & Started & Finished & Excluded & Included & $\mathrm{Age}^{\mathrm{a}}$ & $\mathrm{Sex}^{\mathrm{b}}$ & Race $^{\mathrm{c}}$ \\
\hline 1 & Tom Cruise + Denzel Washington & 479 & 349 & 14 & 355 & $34.7(14.0)$ & $65.97 \%$ & $71.34 \%$ \\
\hline 2 & Ben Affleck + Eddie Murphy & 178 & 126 & 2 & 124 & $35.5(14.8)$ & $65.32 \%$ & $69.35 \%$ \\
\hline 3 & Ben Affleck + Morgan Freeman & 175 & 120 & 3 & 117 & $35.2(14.3)$ & $53.84 \%$ & $71.79 \%$ \\
\hline 4 & Ben Affleck + Samuel L. Jackson & 166 & 118 & 3 & 115 & $34.9(14.7)$ & $68.69 \%$ & $63.47 \%$ \\
\hline 5 & Ben Affleck + Will Smith & 161 & 124 & 0 & 124 & $32.4(13.9)$ & $60.48 \%$ & $66.93 \%$ \\
\hline 6 & Clint Eastwood + Eddie Murphy & 165 & 109 & 3 & 106 & $34.1(15.5)$ & $58.49 \%$ & $59.43 \%$ \\
\hline 7 & Clint Eastwood + Morgan Freeman & 191 & 128 & 5 & 123 & $31.2(13.0)$ & $58.53 \%$ & $69.91 \%$ \\
\hline 8 & Clint Eastwood + Samuel L. Jackson & 189 & 122 & 3 & 119 & $35.8(14.8)$ & $59.66 \%$ & $73.10 \%$ \\
\hline 9 & Clint Eastwood + Will Smith & 171 & 126 & 7 & 118 & $35.7(14.5)$ & $60.16 \%$ & $66.94 \%$ \\
\hline 10 & George Clooney + Eddie Murphy & 174 & 122 & 2 & 120 & $32.4(12.2)$ & $65.00 \%$ & $74.16 \%$ \\
\hline 11 & George Clooney + Morgan Freeman & 165 & 108 & 1 & 107 & $35.7(14.1)$ & $58.87 \%$ & $65.42 \%$ \\
\hline 12 & George Clooney + Samuel L. Jackson & 179 & 116 & 3 & 113 & $35.9(14.0)$ & $61.94 \%$ & $67.25 \%$ \\
\hline 13 & George Clooney + Will Smith & 154 & 108 & 3 & 105 & $32.7(14.4)$ & $65.71 \%$ & $72.38 \%$ \\
\hline 14 & Johnny Depp + Eddie Murphy & 156 & 105 & 1 & 104 & $35.5(16.6)$ & $61.53 \%$ & $66.34 \%$ \\
\hline 15 & Johnny Depp + Morgan Freeman & 210 & 140 & 4 & 136 & $32.8(14.0)$ & $73.52 \%$ & $69.11 \%$ \\
\hline 16 & Johnny Depp + Samuel L. Jackson & 179 & 124 & 0 & 124 & $34.2(14.8)$ & $58.06 \%$ & $66.93 \%$ \\
\hline 17 & Johnny Depp + Will Smith & 186 & 120 & 1 & 119 & $32.0(13.2)$ & $65.54 \%$ & $63.02 \%$ \\
\hline 18 & Ben Affleck + Eddie Murphy & 532 & 356 & 123 & 233 & $38.9(12.2)$ & $67.38 \%$ & $74.67 \%$ \\
\hline 19 & George Clooney + Samuel L. Jackson & 547 & 367 & 111 & 256 & $38.4(13.0)$ & $55.46 \%$ & $69.53 \%$ \\
\hline
\end{tabular}


Table 1

Studies 1-29: Details about the participants

\begin{tabular}{|c|c|c|c|c|c|c|c|c|}
\hline Study & Target Pair & Started & Finished & Excluded & Included & $\operatorname{Age}^{\mathrm{a}}$ & $\operatorname{Sex}^{b}$ & Race $^{\mathrm{c}}$ \\
\hline 20 & Idiosyncratic pair $^{\mathrm{e}}$ & 222 & 186 & 86 & 100 & $25.1(2.38)$ & $53 \%$ & - \\
\hline 21 & Idiosyncratic pair ${ }^{\mathrm{e}}$ & 248 & 220 & 101 & 119 & $25.7(2.36)$ & $50.42 \%$ & - \\
\hline 22 & Idiosyncratic pair ${ }^{\mathrm{e}}$ & 183 & 159 & 7 & 152 & $25.1(2.65)$ & $67.10 \%$ & - \\
\hline 23 & Idiosyncratic pair ${ }^{\mathrm{e}}$ & 182 & 148 & 16 & 132 & $25.0(2.77)$ & $62.12 \%$ & - \\
\hline 24 & Ben Affleck + Eddie Murphy & 507 & 359 & 148 & 211 & $39.8(12.9)$ & $61.61 \%$ & $70.61 \%$ \\
\hline 25 & George Clooney + Samuel L. Jackson & 549 & 394 & 140 & 254 & $39.2(13.3)$ & $60.62 \%$ & $73.22 \%$ \\
\hline 26 & Ben Affleck + Eddie Murphy & 406 & 294 & 76 & 218 & $38.3(12.1)$ & $49.54 \%$ & - \\
\hline 27 & George Clooney + Samuel L. Jackson & 389 & 301 & 71 & 230 & $37.5(13.0)$ & $47.82 \%$ & - \\
\hline 28 & Idiosyncratic pair ${ }^{\mathrm{f}}$ & 650 & 437 & 23 & 414 & $41.3(15.2)$ & $64.49 \%$ & $73.18 \%$ \\
\hline 29 & Idiosyncratic pair ${ }^{\mathrm{f}}$ & 656 & 426 & 67 & 359 & $40.60(14.6)$ & $64.62 \%$ & $77.15 \%$ \\
\hline
\end{tabular}

Note. Demographics for the included samples. ${ }^{\text {a }}$ Mean age. Brackets show standard deviation. ${ }^{\mathrm{b}}$ Proportion of females. ${ }^{\mathrm{c}}$ Proportion of White participants. ${ }^{\mathrm{e}}$ Each participant rated the likability of 10 artists per category. Of those, the pair used in the IAT / EPT was a pair that met the following condition: a difference score of 1 in favor of the member of the stigmatized group (Studies 20-21) or an equal rating of both individuals (Studies 22-23). ${ }^{\mathrm{f}}$ Participants indicated their preference between at least 16 pairs of actors. One of these pairs appeared in the IAT and self-report, based on the experimental condition's criterion (either a self-reported preference for the member from the stigmatized group, or for the member from the dominant group). 


\section{IAT}

The IAT scores showed a different pattern than that of the self-reported evaluation measures. The IAT scores suggested a preference for the White actor in 11 of the studies, were very close to zero (no preference) in 5 of the studies, and suggested a preference for the Black actor only in one study (contrasting Johnny Depp and Will Smith). The Cohen's $d$ s for the preference suggested by the IAT scores ranged from -0.22 to 0.61 (positive effects reflect preference for the White actor). A meta-analysis of all studies with a random-effects model yielded an effect of $d=0.14[0.07 ; 0.22]$. This effect was significantly different from zero $z=$ $3.77, p=.0002$.

\section{Race Evaluation}

Overall, participants tended to report no preference between White people and Black people. The effect-sizes in a comparison of the mean evaluation score to zero were $d=-0.14$ 0.07 , with a meta-analytic effect of $d=-0.01$ [-0.05;0.03], $z=-0.58, p=.56$.

In the online supplement, we report an exploration of the relation between the selfreported race evaluation and the various preference scores. In brief, the self-reported race evaluation correlated with all the preference scores, suggesting that deliberate evaluations of the social groups were related to these evaluations. We also report about the relation between the IAT and self-reported targets and race preference scores. In brief, the IAT was related to self-reported target evaluation, even after controlling for self-reported group evaluations, indicating that the IAT was sensitive to individuating information, and not just to group information. Finally, in the supplement we also report the effects of participants' own race group, measures-order, and IAT block-order, on the self-report and IAT scores. 


\section{Self-Report}

\section{Study}

1. Tom Cruise+Denzel Washington

2. Ben Affleck+Eddie Murphy

3. Ben Affleck+Morgan Freeman

4. Ben Affleck+Samuel L. Jackson

5. Ben Affleck+Will Smith

6. Clint Eastwood+Eddie Murphy

7. Clint Eastwood+Morgan Freeman

8. Clint Eastwood+Samuel L. Jackson

9. Clint Eastwood+Will Smith

10. George Clooney+Eddie Murphy

11. George Clooney+Morgan Freeman

12. George Clooney+Samuel L. Jackson

13. George Clooney+Will Smith

14. Johnny Depp+Eddie Murphy

15. Johnny Depp+Morgan Freeman

16. Johnny Depp+Samuel L. Jackson

17. Johnny Depp+Will Smith

18. Ben Affleck+Eddie Murphy

19. George Clooney+Samuel L. Jackson

\section{Photo-Rating}

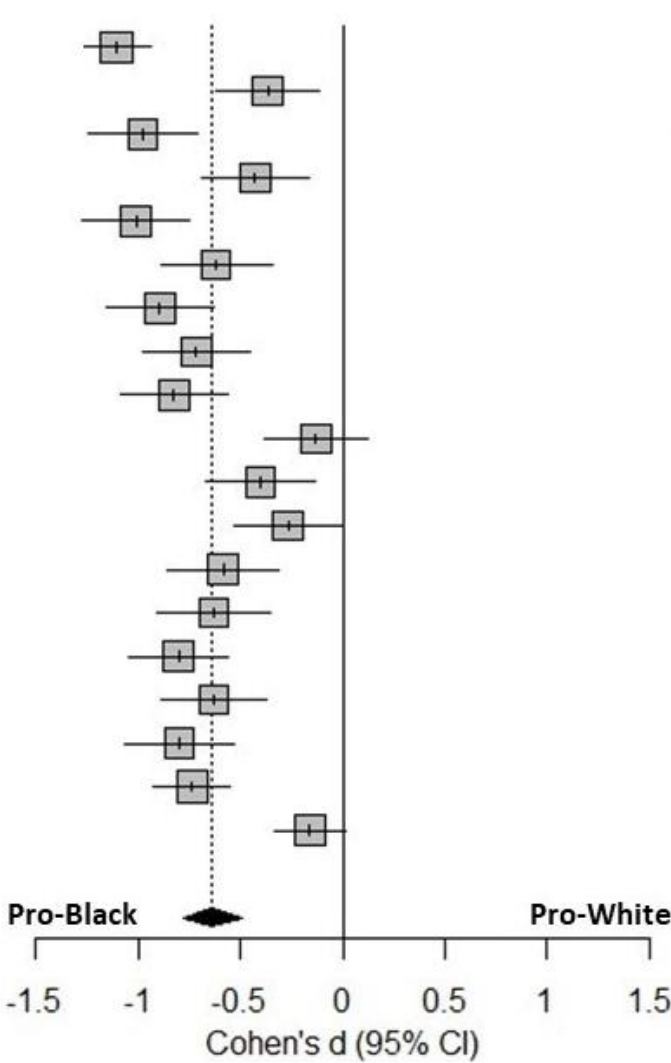

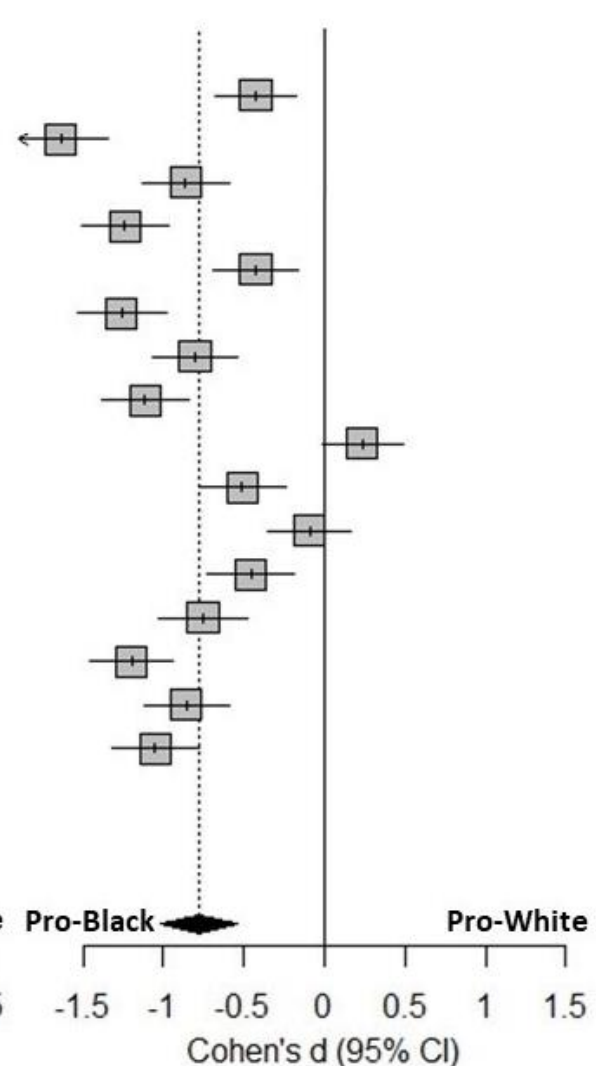

Cohen's d $(95 \% \mathrm{Cl})$
Indirect Measure

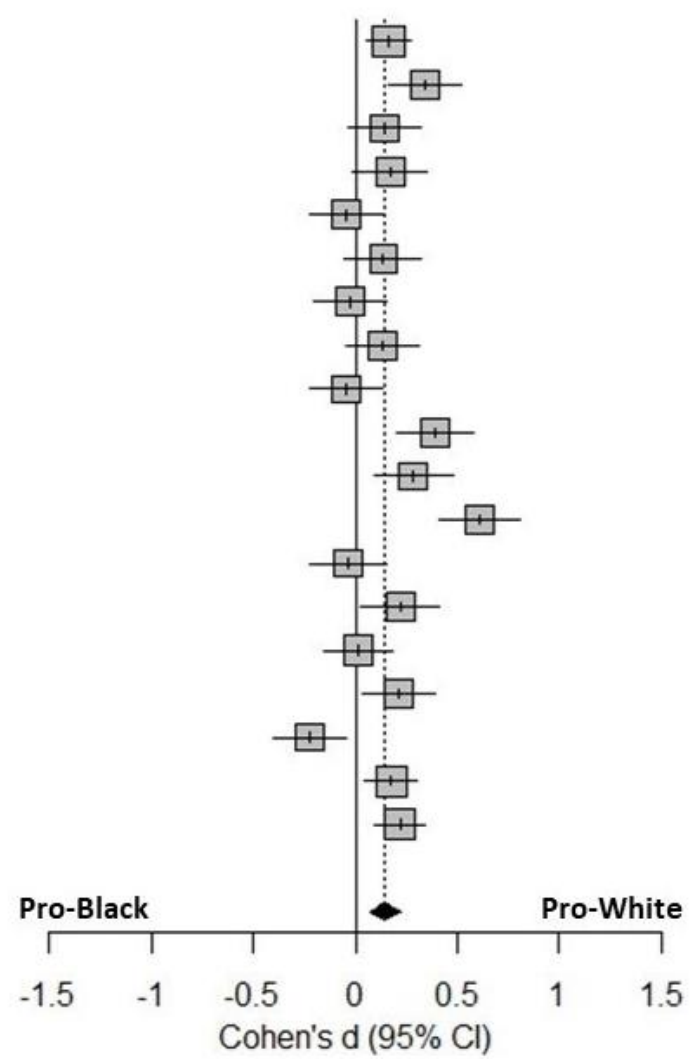

Figure 1. Studies 1-19: Meta-Analyses results for the preferences between the White and the Black actors, computed from self-reported evaluation of the target individuals, self-reported ratings of the targets' photos and an indirect measure. The indirect measure was the IAT in

Studies 1-17 and the EPT in Studies 18-19. 
Table 2

Studies 1-17: Descriptive statistics for the preferences between the actors

\begin{tabular}{|c|c|c|c|c|c|c|}
\hline Study & Pair & Preference & $N$ & Mean & $S D$ & $\alpha^{\mathrm{a}}$ \\
\hline \multirow[t]{2}{*}{1} & Tom Cruise + Denzel Washington & Self-report & 335 & $-6.93 * * *$ & 8.44 & $0.81,0.85$ \\
\hline & & IAT & 335 & $0.07 * *$ & 0.43 & 0.83 \\
\hline \multirow[t]{3}{*}{2} & Ben Affleck + Eddie Murphy & Self-report & 124 & $-2.06^{* * *}$ & 5.18 & $0.67,0.59$ \\
\hline & & Photos & 124 & $-0.35 * * *$ & 0.82 & $0.82,0.76$ \\
\hline & & IAT & 124 & $0.13 * * *$ & 0.4 & 0.82 \\
\hline \multirow[t]{3}{*}{3} & Ben Affleck + Morgan Freeman & Self-report & 117 & $-6.34 * * *$ & 6.87 & $0.74,0.76$ \\
\hline & & Photos & 117 & $-1.54 * * *$ & 1.11 & $0.85,0.87$ \\
\hline & & IAT & 117 & 0.05 & 0.40 & 0.78 \\
\hline \multirow[t]{3}{*}{4} & Ben Affleck + Samuel L. Jackson & Self-report & 115 & $-3.07 * * *$ & 6.53 & $0.81,0.73$ \\
\hline & & Photos & 115 & $-0.74 * * *$ & 1.00 & $0.86,0.85$ \\
\hline & & IAT & 115 & 0.06 & 0.40 & 0.77 \\
\hline \multirow[t]{3}{*}{5} & Ben Affleck + Will Smith & Self-report & 124 & $-6.14 * * *$ & 6.74 & $0.79,0.77$ \\
\hline & & Photos & 124 & $-1.18 * * *$ & 1.09 & $0.89,0.83$ \\
\hline & & IAT & 124 & -0.01 & 0.39 & 0.76 \\
\hline \multirow[t]{3}{*}{6} & Clint Eastwood + Eddie Murphy & Self-report & 106 & $-3.75 * * *$ & 5.93 & $0.70,0.74$ \\
\hline & & Photos & 106 & $-0.40 * * *$ & 0.92 & $0.79,0.83$ \\
\hline & & IAT & 106 & 0.05 & 0.43 & 0.82 \\
\hline \multirow[t]{3}{*}{7} & Clint Eastwood + Morgan Freeman & Self-report & 123 & $-6.43 * * *$ & 7.71 & $0.77,0.64$ \\
\hline & & Photos & 123 & $-1.18 * * *$ & 1.10 & $0.82,0.89$ \\
\hline & & IAT & 123 & -0.01 & 0.44 & 0.83 \\
\hline \multirow[t]{3}{*}{8} & Clint Eastwood + Samuel L. Jackson & Self-report & 119 & $-4.47 * * *$ & 7.98 & $0.80,0.67$ \\
\hline & & Photos & 119 & $-0.79 * * *$ & 1.09 & $0.85,0.84$ \\
\hline & & IAT & 119 & 0.05 & 0.40 & 0.80 \\
\hline \multirow[t]{3}{*}{9} & Clint Eastwood + Will Smith & Self-report & 118 & $-5.64 * * *$ & 6.68 & $0.77,0.77$ \\
\hline & & Photos & 118 & $-1.04 * * *$ & 1.08 & $0.84,0.90$ \\
\hline & & IAT & 118 & -0.02 & 0.45 & 0.85 \\
\hline \multirow[t]{3}{*}{10} & George Clooney + Eddie Murphy & Self-report & 120 & -0.76 & 6.35 & $0.76,0.79$ \\
\hline & & Photos & 120 & $0.21 *$ & 1.04 & $0.86,0.79$ \\
\hline & & IAT & 120 & $0.16^{* * *}$ & 0.41 & 0.8 \\
\hline \multirow[t]{3}{*}{11} & George Clooney + Morgan Freeman & Self-report & 107 & $-2.39 * * *$ & 5.83 & $0.82,0.80$ \\
\hline & & Photos & 107 & $-0.49 * * *$ & 0.83 & $0.90,0.81$ \\
\hline & & IAT & 107 & $0.12 * *$ & 0.44 & 0.84 \\
\hline \multirow[t]{2}{*}{12} & George Clooney + Samuel L. Jackson & Self-report & 113 & $-1.56^{* *}$ & 4.93 & $0.78,0.70$ \\
\hline & & Photos & 113 & -0.08 & 0.70 & $0.92,0.84$ \\
\hline
\end{tabular}


Table 2

Studies 1-17: Descriptive statistics for the preferences between the actors

\begin{tabular}{|c|c|c|c|c|c|c|}
\hline Study & Pair & Preference & $N$ & Mean & $S D$ & $\alpha^{\mathrm{a}}$ \\
\hline & & IAT & 113 & $0.24 * * *$ & 0.39 & 0.78 \\
\hline \multirow[t]{3}{*}{13} & George Clooney + Will Smith & Self-report & 105 & $-3.57 * * *$ & 5.63 & $0.77,0.72$ \\
\hline & & Photos & 105 & $-0.41 * * *$ & 0.72 & $0.86,0.86$ \\
\hline & & IAT & 105 & -0.01 & 0.43 & 0.82 \\
\hline \multirow[t]{3}{*}{14} & Johnny Depp + Eddie Murphy & Self-report & 104 & $-3.79 * * *$ & 6.43 & $0.80,0.71$ \\
\hline & & Photos & 104 & $-0.68 * * *$ & 1.18 & $0.83,0.74$ \\
\hline & & IAT & 104 & $0.09 *$ & 0.40 & 0.78 \\
\hline \multirow[t]{3}{*}{15} & Johnny Depp + Morgan Freeman & Self-report & 136 & $-5.05 * * *$ & 7.34 & $0.84,0.77$ \\
\hline & & Photos & 136 & $-1.21 * * *$ & 1.14 & $0.84,0.88$ \\
\hline & & IAT & 136 & 0.01 & 0.44 & 0.83 \\
\hline \multirow[t]{3}{*}{16} & Johnny Depp + Samuel L. Jackson & Self-report & 124 & $-4.01 * * *$ & 8.27 & $0.84,0.74$ \\
\hline & & Photos & 124 & $-0.81 * * *$ & 1.11 & $0.86,0.81$ \\
\hline & & IAT & 124 & $0.08^{*}$ & 0.39 & 0.72 \\
\hline \multirow[t]{3}{*}{17} & Johnny Depp + Will Smith & Self-report & 119 & $-4.93 * * *$ & 6.35 & $0.85,0.67$ \\
\hline & & Photos & 119 & $-1.09 * * *$ & 1.17 & $0.87,0.89$ \\
\hline & & IAT & 119 & $-0.10^{*}$ & 0.45 & 0.83 \\
\hline
\end{tabular}

Note. In all measures, positive values reflect a preference for the White actor over the Black actor. The self-reported preferences were computed as difference scores, resulting in a range of -100 to 100 for the self-reported preference between the actors and a range of -6 to 6 for the photos ratings. Asterisks refer to the statistical significance of a comparison of the mean to zero (which indicates no preference): ${ }^{*} \mathrm{p}<.05,{ }^{* *} \mathrm{p}<.01, * * * \mathrm{p}<.001$. ${ }^{\mathrm{a}}$ For the self-report and photo evaluations, the left value refers to the alpha for the White target items, and the right value refers to the alpha for the Black target items.

\section{Discussion}

Across 17 studies using various stimuli, we found a consistent discrepancy between self-report and the IAT, assessing the evaluations of well-known individuals. Self-reported evaluations favored the Black actors whereas IAT scores almost never suggested a preference 
for the Black actors, showing, on average, a preference for the White actors. These results suggest that group membership had a large influence on the automatic evaluation of wellknown individuals, despite the long familiarity with these individuals. Because people reported no preference between White and Black people, and reported preference for the Black actor over the White actor, it seems that individuating information determined the deliberate preference but was unable to reverse the effect of the automatic group preference on the automatic preference between the individuals.

\section{Studies 18-19: Measuring Automatic Evaluation with Evaluative Priming}

Because research suggests that the IAT is sometimes sensitive to factors other than automatic evaluation (e.g., Rothermund \& Wentura, 2001, 2004), we sought for more evidence with a different indirect measure that was developed to measure automatic evaluation, the EPT. If we find the same results with the EPT, it would increase the confidence that our findings indeed pertain to automatic evaluation, rather than other processes that might influence the IAT. If we find different results, it would provide suggestive evidence about the distinction between the constructs captured by the IAT and EPT (Vianello \& Bar-Anan, in press). Additionally, in these studies we measured participants' reported familiarity with the actors. In Studies 1-17, we assumed that participants were familiar with the actors because they were famous. Using a familiarity measure in the present studies, we attempted to rule out the possibility that the previous results were biased by a minority of the participants who were unfamiliar with the actors.

\section{Methods}

\section{Participants}

Participants were volunteers at the Project Implicit website (implicit.harvard.edu; Nosek, 2005). We excluded participants who had > 40\% error trials in the EPT (Bar-Anan \& Nosek, 2014), and participants who reported no familiarity with the actors (see Table 1). 


\section{Procedure and Measures}

In Studies 18-19, we used two pairs of actors: Ben Affleck and Eddie Murphy (Study 18), and George Clooney and Samuel L. Jackson (Study 19). In Studies 2 and 12, these pairs showed clear discrepancy in the direction of the self-report and IAT scores (though a discrepancy was apparent in all studies). That is, we selected target pairs in which the selfreport and IAT were clearly in opposite directions, to allow for a clear inference about the meaning of the discrepancy (i.e., no alternative account related to the lower reliability of the indirect measures, that might lead to smaller effect sizes, relative to more reliable selfreports). Admittedly, this strategy for increasing the likelihood of clear statistical inference reduces the generalizability of our findings. The self-report measure was the same as the in Studies 1-17 (liking measure).

Evaluative Priming Task (EPT Fazio et al., 1986). The primes we used for the EPT were the same ten photos of the White and Black actors (five each) used in the IAT (Studies 2 and 12). Participants classified 20 target stimuli to the categories Good (positive, pleasant, good, outstanding, beautiful, magnificent, marvelous, excellent, appealing, delightful) and Bad (negative, bad, horrible, miserable, hideous, dreadful, painful, repulsive, awful, ugly). There were three blocks, each containing 60 trials ( 15 trials per prime-target combination). The sequence of stimuli within each trial was based on a previous (unpublished) study in our lab that showed good measurement quality. Specifically, each trial started with a fixation stimulus displayed for $500 \mathrm{~ms}$, replaced by a prime stimulus that appeared for $200 \mathrm{~ms}$, until the appearance of the target words that appeared until the participant's response. After error responses, a red X appeared for $1500 \mathrm{~ms}$. The inter-trial interval was $500 \mathrm{~ms}$. The order of the trials was random. Similarly, the assignment of stimuli to each prime-target condition was random. 
Prior to the score computation, latencies were log-transformed, and outlier trials and participants were excluded. We excluded incorrect responses and trials with latency exceeding the mean of the relevant prime-target condition in 2.5 SDs (Bar-Anan \& Nosek, 2014). For each prime-target condition, within each block, we computed the mean of the log transformed RTs. We subtracted the means of the conditions White-Good and Black-Bad from the means of the conditions Black-Good and White-Bad, and divided that difference by the block's standard deviation. Finally, we averaged the standardized difference scores of the three blocks to a single score. This standardization was based on the standardization performed in the computation of the IAT D score. This standardization was found to outperform other common computations of the scores (e.g., Axt et al., 2020; Bar-Anan \& Nosek, 2014).

Familiarity. At the end of the study, we measured the participants' familiarity with the two actors. Participants responded to two questions about each actor. The first question was How familiar were you with the actor [name of actor] before this study? With the response options 1 - Extremely familiar 2 - Moderately familiar, 3 - Slightly familiar, and 4 - Never heard of him before. The second question was To the best of your knowledge, is [name of actor] a Black person or a White person? The response options were A Black person (I am sure), A Black person (I think), A Black Person (I guess), A White person (I guess), A White person (I think), A White person (I am sure). We excluded from the analyses participants who responded 'Never heard of him before' about at least one actor, or indicated the wrong race of at least one actor. That exclusion (used also in Studies 20-29) ruled out an alternative account to the discrepancy findings: participants unfamiliar with the actors judged by the actors' race, whereas participants familiar with the actors judged by the individuating information.

\section{Results}

Table 3 presents the descriptive statistics for the preference between the actors. 
Table 3

Studies 18-19: Descriptive statistics for each measure

\begin{tabular}{lllllll}
\hline Study & Pair & Preference & $N$ & $M$ & $S D$ & $\alpha^{\mathrm{a}}$ \\
\hline 18 & Affleck + Murphy & Self-report & 233 & $-0.92^{* * *}$ & 1.25 & $0.72,0.68$ \\
& & EPT & 233 & $0.06^{* * *}$ & 0.38 & 0.39 \\
\multirow{2}{*}{19} & Clooney + Jackson & Self-report & 256 & $-0.23 * * *$ & 0.98 & $0.65,0.64$ \\
& & EPT & 256 & $0.08^{* *}$ & 0.36 & 0.44 \\
\hline
\end{tabular}

Note. Positive values indicate stronger preference for White people. Asterisks indicate comparison of the mean to zero. $* \mathrm{p}<.05, * * \mathrm{p}<.01, * * * \mathrm{p}<.001 .{ }^{\mathrm{a}}$ For the self-report, the left value refers to the internal consistency of the White target items, and the right value refers to the alpha for the Black target items.

\section{Self-Reported Evaluation}

In line with the previous studies, participants reported a preference for the Black actor over the White actor, $t s(232,255)=-11.30,-3.70, p s<.001, d s=-0.74,-0.23, B F_{10}>1,000$, 50.80 .

\section{EPT}

Similarly to the results found with the IAT in the previous studies, participants' EPT scores suggested a preference for the White actor over the Black actor, $t \mathrm{~s}(232,255)=2.69$, $3.51, p \mathrm{~s}=.008,<.001, d \mathrm{~s}=0.18,0.22, B F_{10}=2.46,26.80$.

\section{Discussion}

Studies 18-19 replicated the results of Studies 1-17 with a different indirect measure, the EPT. As before, participants showed a clear preference for the White actors over the Black actors in their indirectly-measured evaluations, despite self-reporting a strong preference for the Black actors over the White actors. These results strongly reduce the concern that our 
findings are unique to the IAT, and increase the likelihood that they indeed capture automatic evaluation.

\section{Studies 20-23: Generalization to Other Participant Population and Another Social Group}

In Studies 20-23, we tested the generalizability of the discrepancy findings to other social groups (Old and Young people) and to non-American population (Israelis). We chose the groups Old and Young people because, like race, age is processed relatively quickly, and is commonly used to categorize individuals to groups (Brooks \& Freeman, 2018). We tested whether the preference measured with an indirect measure would be less favorable of Old famous people (compared to young famous people) than the preference measured with a direct measure.

The paradigm used in Studies 20-23 was slightly different than that of Studies 1-19. Specifically, in the previous studies we chose as stimuli Black actors that were rated by an independent sample as more popular (i.e., liked more) than the White actors that we chose. In the present studies, partly because we did not have popularity ratings among Israelis, we selected for each participant one member of the dominant group (a young/White actor or musician) and one member of the stigmatized group (an old/Black actor or musician), based on the participant's reported rating of the actors. We chose a member of the stigmatized group whom the participants preferred over the member of the dominant group (Studies 20-21), or individual members that the participants rated as equally liked (Studies 22-23). In other words, we kept the deliberate preference constant for all participants, and examined whether the automatic preference would be biased in favor of the member of the dominant group. As the indirect measures, we used the IAT in Studies 20-21, and the EPT in Studies 22-23. 


\section{Methods}

\section{Participants}

Participants were 20-29 years old secular Israelis recruited on a survey company (Midgam), and paid 10 NIS ( \$3) in exchange for their participation in a 15-min study. We excluded participants who had $>10 \%$ fast trials in the IAT (Studies 20-21) or $>40 \%$ error trials in the EPT (Studies 22-23), as in Studies 1-19, and participants who reported no familiarity with at least one of the two individual targets (Table 1).

\section{Procedure and Measures}

Participants completed the study in Hebrew. They first rated the likability (on a scale of 1-7) and familiarity (on a scale of 0: Never heard of him to 3: I was exposed to him a lot) of 40 American actors and musicians. We used one set of 40 of artists (10 per category: White, Black, young, old, see Table S2) for Studies 20-21, and a set of other 40 artists for Studies 2223. Next, participants completed an IAT (Studies 20-21) or EPT (Studies 22-23). For each participant, we selected a White person and a Black person (Studies 20, 22), or a young person and an old person (Studies 21, 23). The characteristics and data preparation of the IAT and EPT were the same as in our previous studies.

Stimuli selection. In Studies 20-21, we selected for each participant a member of the stigmatized group who was rated by the participant one point higher than a member of the dominant group (e.g., Brad Pitt and Chris Rock, for a participant who rated Pitt '4' and Rock ' 5 '). In Studies 22-23, we selected two individuals who were rated exactly the same by the participant (e.g., Russell Crowe and Lenny Kravitz, for a participant who rated both of them ' 5 '). If there was more than one pair that fit that requirement, one of these pairs was selected randomly. 


\section{Results}

Table 4 presents the descriptive statistics for the scores of the indirect measures.

Figures 2-3 show the distribution of the IAT and EPT scores across the various pairs of artists for each social group (race, age).

\section{Table 4}

Studies 20-23: Descriptive statistics for the automatic measure

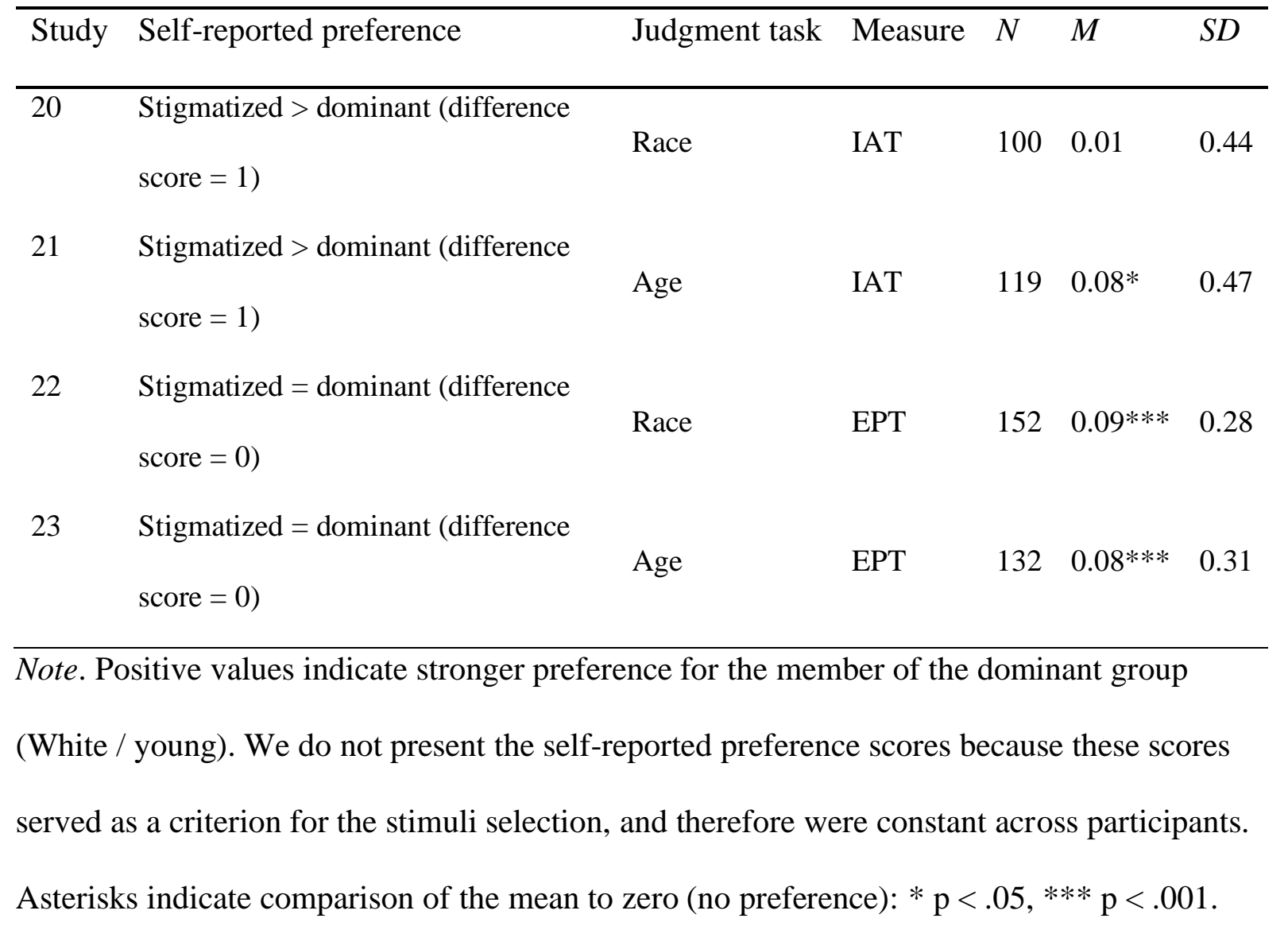

\section{Indirect Measures}

The scores distribution appears in Figures 2-3. When participants reported they preferred the artist from the stigmatized group over the artist from the dominant group (Studies 20-21), the IAT scores for race targets showed no difference in the preference between the target individuals, and the IAT scores for age targets showed a small pro-young 
preference, $t \mathrm{~s}(99,118)=0.27,2.00, p \mathrm{~s}=.78, .04, d \mathrm{~s}=0.03,0.18, B F_{10}=0.115,0.692$. When participants reported that they like the two individual targets equally (Studies 22-23), the EPT scores showed a preference for the member of the dominant group over the member of the stigmatized group, $t \mathrm{~s}(151,131)=4.03,3.18, p \mathrm{~s}<.001, .002, d \mathrm{~s}=0.32,0.28, B F_{10}=178$, 11.60

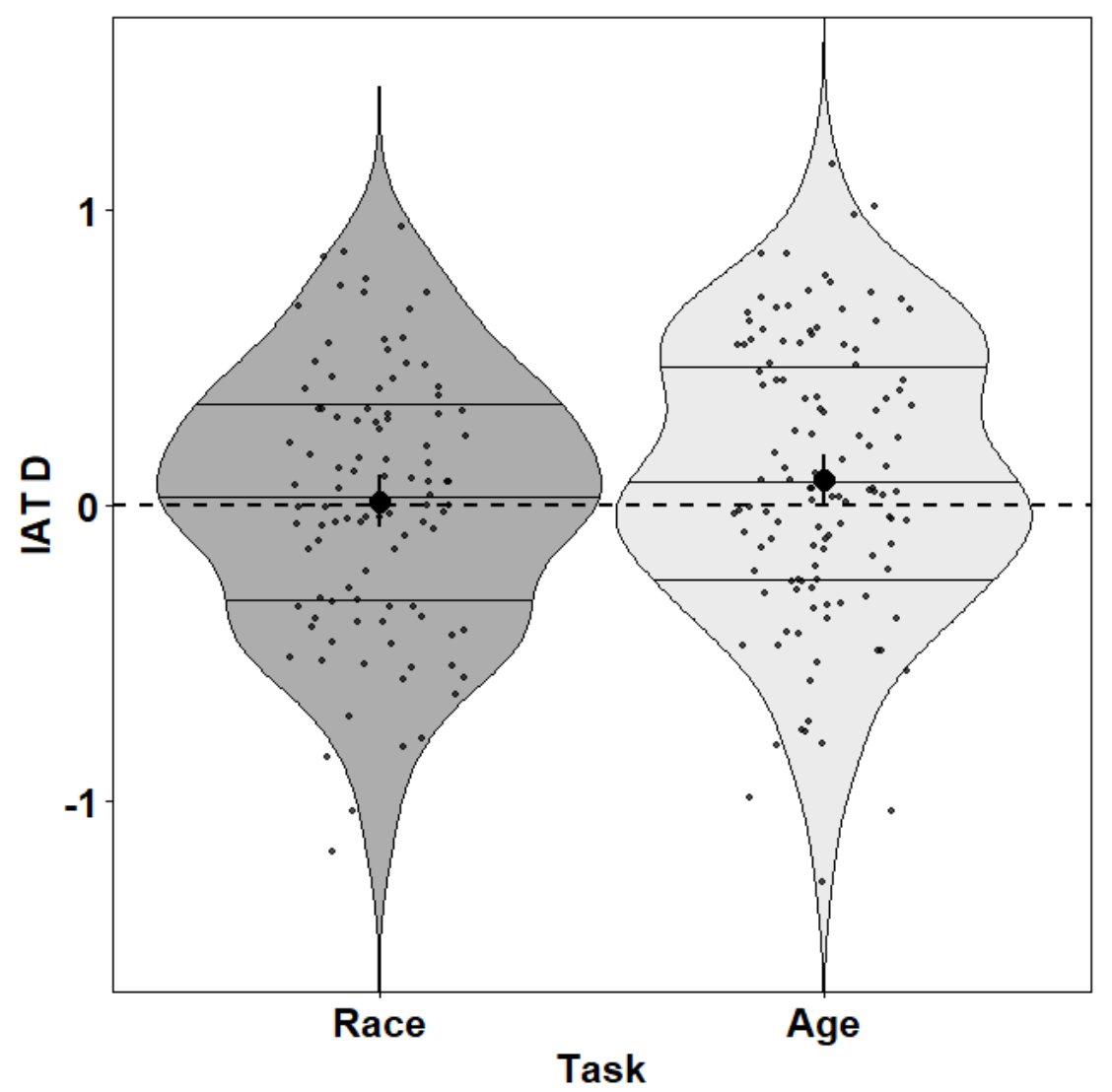

Figure 2. IAT D mean scores with a 95\% CI for each type of judgment task (race [Study 20], age [Study 21). Each dot represents a single observation. The straight lines mark the $25 \%$, $50 \%$, and $75 \%$ quantiles. The dashed line marks the zero point. Positive scores indicate preference for the member of the dominant group. 


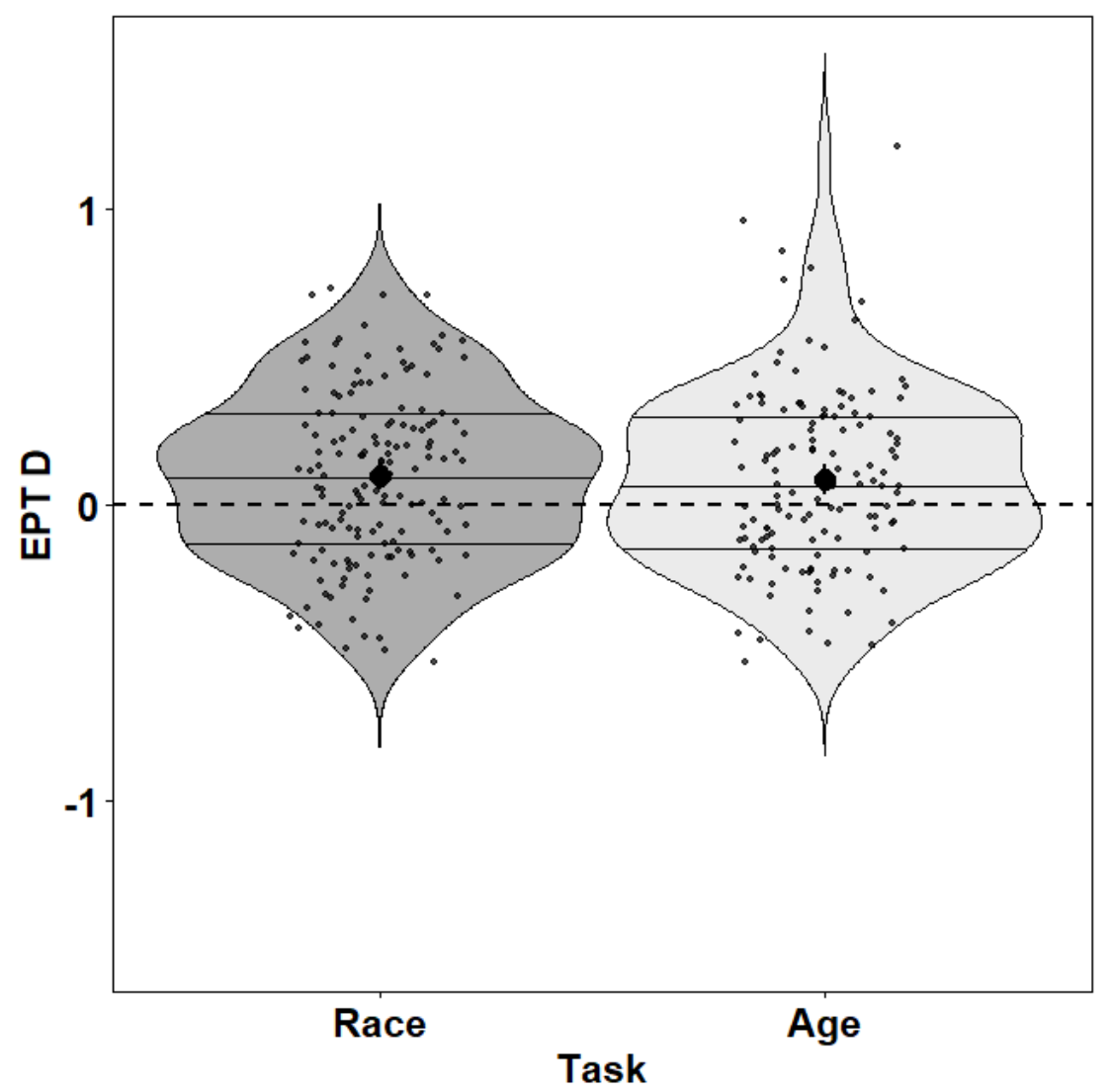

Figure 3. EPT D mean scores with a 95\% CI for each type of judgment task (race [Study 22], age [Study 23). Each dot represents a single observation. The straight lines mark the $25 \%$, $50 \%$, and $75 \%$ quantiles. The dashed line marks the zero point. Positive scores indicate preference for the member of the dominant group.

\section{Discussion}

In Studies 20-23, we found the same discrepancy that we found in Studies 1-19, extending our results to the evaluation of another stigmatized social group (Old people) and to a non-American population (Israelis). As before, participants showed a preference toward the member of the dominant group on the indirect measures, despite reporting no such preference (Studies 22-23), or showed no preference between the two group members, or a small prodominant preference on the indirect measures, despite reporting a preference for the member of the stigmatized group (Studies 20-21). These results suggest that the effect of group 
membership (relatively to individuating information) is stronger on automatic evaluation than on deliberate evaluation.

\section{Studies 24-25: The Effect of Exposure to Visual Characteristics of the Groups}

In Studies 24-25, we examined whether direct and indirect measures of evaluation of well-known members of a stigmatized and a dominant social group are sensitive to the display of the targets with their distinct visual group characteristics (i.e., their racial features). We manipulated between participants, whether the target individuals (a Black actor and a White actor) appeared in photos or only by names. This manipulation provided evidence pertinent to a couple of questions. First, we assumed that group membership was the reason for the discrepancy that we found in the previous studies. That seems highly probable given the large number of different stimuli we used (e.g., had we used only Tom Cruise and Denzel Washington in all our studies, it would have been more difficult to rule out other differences between the actors as the reason for our findings). Nevertheless, if we find a stronger discrepancy when the visual characteristics of the targets' group were clearly seen, that would provide experimental evidence that group membership is indeed behind the discrepancy that we found.

A second question that the manipulation in Studies 24-25 helped investigate is whether the prejudice suggested by the scores of the indirect measures in Studies 1-23 is a result of an automatic activation of the evaluative representation of the target individuals, or the evaluative representation of the social group, activated by the group characteristics (in this case, physical appearance). Long familiarity with the individual targets might fail to eradicate automatic prejudice because the automatic activation of negative valence is a reaction to the group characteristic (e.g., skin tone) rather than a reaction to the individual person. People might gain experience in judging Eddie Murphy positively, but they also continue to judge, overall, individuals with Black characteristics negatively. As a result, the mental 
representation of Eddie Murphy might not be associated, in people's memory, with negative valence; only his Black characteristics (e.g., skin tone) would be associated with negative valence. In that case, we expect to see a stronger automatic preference for the White individual over the Black individual, when the individuals appear with their physical characteristics (i.e., in photos) than when they appear without their physical characteristics (i.e., by name).

\section{Methods}

\section{Participants}

The details about the participants appear in Table 1.

\section{Procedure and Measures}

As in Studies 18-19, we used two pairs of actors: Ben Affleck and Eddie Murphy (Study 24), and George Clooney and Samuel L. Jackson (Study 25). The main modification in Studies 24-25 was that the stimuli were different, depending on the exposure condition, assigned randomly. Participants in the visual characteristics absent condition saw only the actors' names in all measures. For the IAT, the categories labels were the actors' full names, and the stimuli were the actors' first name, last name, or both, written either in regular or uppercase letters (e.g., Eddie Murphy, MURPHY, EDDIE, and EDDIE MURPHY). For the visual characteristics present condition, the labels were the actors' names, and the stimuli were the actors' photos, which showed clear visual characteristics of the actors' race groups (as in the previous studies).

The wording of the self-report questions in the visual characteristics absent condition referred to the actor's name (e.g., How likable is [actor's name]?). In the visual characteristics present condition, the question referred to the person in the photo (e.g., How likable do you think that this person is?), and was presented next to the actor's photo. The self-report questionnaire included the three liking items from the previous studies, without the 
thermometer items. As in Studies 1-19, participants completed the IAT and the self-reported liking measures in a random order.

Familiarity. After the evaluation measures, participants responded to the same familiarity questions as in Studies 18-23.

\section{Results}

Table 5 presents the descriptive statistics and reliability for the preference between the actors and the social groups.

\section{Self-Reported Evaluation}

In their self-reports, participants favored the Black actor over the White actor in both studies, in all conditions. Descriptively, that pro-Black preference was larger when the actors were presented in photos than when they were presented only by names. However, that effect was non-significant in Study 24, $t(209)=-1.92, p=.056, d=-0.26, B F_{10}=0.843$, and tiny and non-significant in Study 25, $t(252)=-0.35, p=.724, d=-0.04, B F_{10}=0.146$. We computed Bayes factors (BF) using the jmv package in R (version 0.9.6.1, Selker et al., 2019) with the default Jeffreys prior (Rouder et al., 2012), in search of more information for statistical inference. We interpreted the strength of evidence based on suggestions by Jeffreys (Appendix B, 1961). When computing BFs for the hypothesis that self-reported preference for the White actor was larger in the visual characteristics present condition than in the visual characteristics absent condition (i.e., opposite of the present results pattern), the values were $B F_{01}=18.62,9.34$, indicating strong evidence against that hypothesis.

\section{IAT}

The visual characteristics present condition replicated the findings of Studies 2 and 12: despite self-reported preference for the Black actor, participants' IAT scores suggested a preference for the White actors (Table 5). Although discrepancy also occurred in the visual characteristics absent condition, in that condition the IAT scores suggested no preference 
between the actors. In other words, the preference for the White actor was stronger in the visual characteristics present condition than in the visual characteristics absent condition, $t \mathrm{~s}(209,252)=2.80,3.82, p \mathrm{~s}=.006,<.001, d \mathrm{~s}=0.39,0.48, B F_{10}=5.77,122$, in Studies 24 and 25 , respectively.

\section{Table 5}

Studies 24-25: Descriptive statistics for each measure for each exposure condition

\begin{tabular}{|c|c|c|c|c|c|c|c|}
\hline \multirow[b]{2}{*}{ Study } & \multirow[b]{2}{*}{ Pair } & \multirow[b]{2}{*}{ Preference } & \multicolumn{3}{|l|}{ Visual } & \multirow[b]{2}{*}{$S D$} & \multirow[b]{2}{*}{$\alpha^{\mathrm{a}}$} \\
\hline & & & Characteristics & $N$ & $M$ & & \\
\hline \multirow[t]{6}{*}{24} & Affleck + Murphy & Self-report & Present & 111 & $-1.17 \mathrm{a} * * *$ & 1.30 & $0.72,0.64$ \\
\hline & & & Absent & 100 & $-0.84_{a} * * *$ & 1.19 & $0.71,0.55$ \\
\hline & & IAT & Present & 111 & $0.19 \mathrm{a} * * *$ & 0.36 & 0.80 \\
\hline & & & Absent & 100 & $0.04_{b}$ & 0.40 & 0.81 \\
\hline & & Race & Present & 111 & $0.00_{\mathrm{a}}$ & 0.49 & 0.65 \\
\hline & & & Absent & 100 & $0.01_{\mathrm{a}}$ & 0.50 & 0.71 \\
\hline \multirow[t]{6}{*}{25} & Clooney + Jackson & Self-report & Present & 137 & $-0.23_{\mathrm{a}} * *$ & 0.89 & $0.72,0.75$ \\
\hline & & & Absent & 117 & $-0.19 \mathrm{a} * *$ & 0.76 & $0.71,0.70$ \\
\hline & & IAT & Present & 137 & $0.23_{\mathrm{a}} * * *$ & 0.39 & 0.80 \\
\hline & & & Absent & 117 & $0.05_{b}$ & 0.38 & 0.75 \\
\hline & & Race & Present & 137 & $0.06_{\mathrm{a}}$ & 0.46 & 0.66 \\
\hline & & & Absent & 117 & $0.00_{\mathrm{a}}$ & 0.51 & 0.72 \\
\hline
\end{tabular}

Note. Within each measure within each study, different subscripts indicate significant difference between the two conditions. Asterisks indicate comparison of the mean to the point of no preference (zero): $* * \mathrm{p}<.01, * * * \mathrm{p}<.001$. ${ }^{\mathrm{a}}$ For the self-report, the left value refers to the alpha for the White target items, and the right value refers to the alpha for the Black target items. 


\section{Race Evaluation}

In all the conditions in both studies, participants reported no preference between Black and White people (Table 5). There was no effect of the exposure manipulation on the selfreported preference between White and Black people, in Studies 24 and 25, respectively, $t \mathrm{~s}(209,252)=0.284,1.120, p \mathrm{~s}=.776, .262, d \mathrm{~s}=0.04,0.14, B F_{10}=0.156,0.251$.

\section{Discussion}

When the target individuals appeared visually, with the visual characteristics of their group, the pro-dominant preference on the IAT was larger than when the targets were presented only textually, with no clear group characteristics, whereas self-reported preference was the same in both conditions. This result is compatible with the hypothesis that the discrepancy that we found in the previous studies between the self-report and the indirect measures is due to a larger influence of group membership (relatively to individuating information) on automatic than on deliberate evaluation. The result is also compatible with the hypothesis that an automatic evaluative reaction to (visual) characteristics of the groups contributed to the automatic evaluation of the individual targets. This contribution may reflect an evaluation that is dependent of group-categorization and that activates the group-related prejudice, or an evaluation of the targets' (racially prototypical) facial features independent of group-categorization (Livingston \& Brewer, 2002), or both. However, although the discrepancy was smaller when participants saw only the names of the targets, it was not completely diminished; the mean IAT score was zero rather than negative (suggestive proBlack preference), as it was in the self-reported evaluation. The lingering discrepancy between the IAT score and the self-report might suggest that the individual targets and their group characteristics each automatically activates the evaluation of the groups. In other words, the evidence from Studies 24-25 is compatible with the possibility that exposure to visual group characteristics increases the effect of group membership on automatic 
evaluation, but that even without such strong characteristics, automatic evaluation is more favorable toward members of the dominant group than deliberate evaluation.

\section{Studies 26-27: The Relation Between Deliberate and Automatic Evaluations of the}

\section{Groups and of the Individuals}

In our interpretation of the results of the previous studies, we attributed people's automatic preference for the member of dominant group over the member of the stigmatized group to an automatic preference for the dominant group over the stigmatized group. This was based on the well-documented finding that supposed measures of automatic evaluation find preferences for dominant groups (in the present case, Young people and White people, e.g., Nosek, Smyth, et al., 2007). However, in the previous studies, we only measured deliberate (i.e., self-reported) preference between the social groups. As detailed in the online supplement, the self-reported pro-White preference was equally related to the self-reported preference (average $r=.174$ [actors preference], .221 [photo rating preference]) and the indirectly measured preference (average $r=.169$ ) between the individual targets. These results are of limited informative value because they are missing the indirectly measured preference between the social groups. In the next set of studies, we added an indirect measure of race preference. We expected to find a pro-White preference on that measure - the hypothesized reason for the automatic (indirectly measured) pro-White preference between the individual targets. If automatic race preference was indeed the reason for the findings so far, we might see evidence for that in the relations between the evaluations of race groups and the evaluations of the targets: Scores on an IAT developed to measure the preference between the targets would be more strongly related to scores on an IAT developed to measure preference between the groups than to the self-reported preference between the groups, whereas the self-reported preference between the targets would show the opposite pattern. 


\section{Methods}

\section{Participants}

Participants were recruited online via the Prolific website (https://prolific.ac). They were paid $£ 2$ in exchange for their participation in a 22-min study. We recruited only Americans. Further details about the participants appear in Table 1.

\section{Measures and Procedure}

In Studies 26-27, we used the same pairs of actors as in Studies 18-19 (and 24-25). The measures were the same as in Studies 1-19 (including the photo ratings and the familiarity questionnaire), with the following modifications: we modified the three items of the liking measure to directly assess preference between the two actors (rather than use difference scores as we did in the previous studies). An example item is Whom do you like more, [name of White actor] or [name of Black actor]? The 7-point response scale ranged from I like [name of Black actor] extremely more than [name of White actor] to I like [name of White actor] extremely more than [name of Black actor]. The purpose of that modification was to decrease the methodological difference between the self-report measure and the indirect measure of the actors' evaluation (the IAT does not measure the evaluation of each actor separately, but one relative to the other), to eliminate that difference as a possible alternative account for the discrepancy findings.

We added two IATs: A Race-IAT (R-IAT) assessing automatic preference between White and Black people, and a Flowers-insects-IAT (FI-IAT), assessing automatic preference between flowers and insects. We included the FI-IAT to control for common method variance between the R-IAT and the actors-IAT (A-IAT). In the A-IATs we used the same stimuli as in the IATs in the previous studies. The labels for the categories White and Black people in the R-IAT were "White people" and "Black people" and the stimuli were grayscale photos of African American and European American faces (half male, half female), cropped at the chin 
and forehead (Nosek et al., 2007). The category labels in the FI-IAT were "Flowers" and "Insects" with photos of flowers and insects as the stimuli. Participants completed all the IATs before or after (randomly assigned) completing all the self-report measures. The order of the IATs was FI-IAT, A-IAT, R-IAT. The order of the self-report measures was: Actors evaluation, photo evaluation, race evaluation. Because we added the FI-IAT only to estimate IAT method variance, we administrated it before the other IATs to help participants practice the IAT before the more theoretically important IATs to allow practice in the IAT with a theoretically meaningless task. The race measures were last in order to decrease the likelihood that participants would think about the actors in racial terms.

\section{Results}

Table 6 presents the descriptive statistics and reliability in both studies.

Table 6

Studies 26-27: Descriptive statistics for each measure

\begin{tabular}{|c|c|c|c|c|c|c|}
\hline Study & Pair & Preference & $N$ & $M$ & $S D$ & $\alpha^{\mathrm{a}}$ \\
\hline \multirow[t]{6}{*}{26} & \multirow[t]{6}{*}{ Affleck + Murphy } & Self-report actors & 218 & $-0.60 * * *$ & 1.04 & 0.72 \\
\hline & & Photos & 218 & $-0.65 * * *$ & 1.12 & $0.91,0.81$ \\
\hline & & Self-report race & 218 & $0.16^{* *}$ & 0.82 & 0.84 \\
\hline & & IAT actors & 218 & $0.16^{* * *}$ & 0.39 & 0.78 \\
\hline & & IAT race & 218 & $0.36^{* * *}$ & 0.37 & 0.75 \\
\hline & & IAT flowers-insects & 218 & $0.65 * * *$ & 0.4 & 0.83 \\
\hline \multirow[t]{5}{*}{27} & \multirow[t]{5}{*}{ Clooney + Jackson } & Self-report actors & 230 & $-0.37 * * *$ & 1.04 & 0.74 \\
\hline & & Photos & 230 & -0.07 & 1.02 & $0.94,0.92$ \\
\hline & & Self-report race & 230 & $0.19 * * *$ & 0.86 & 0.93 \\
\hline & & IAT actors & 230 & $0.20 * * *$ & 0.37 & 0.74 \\
\hline & & IAT race & 230 & $0.30 * * *$ & 0.37 & 0.75 \\
\hline
\end{tabular}


IAT flowers-insects $\quad 230 \quad 0.67 * * * \quad 0.37 \quad 0.81$

Note. Larger numbers indicate stronger preference for White people, the White actor, or flowers. Asterisks indicate the statistical significance of the comparison of the mean to zero: $* * \mathrm{p}<.01, * * * \mathrm{p}<.001 .{ }^{\mathrm{a}}$ For the photo evaluations, the left value refers to the internal consistency of the White target items, and the right value refers to the alpha for the Black target items.

\section{Self-Reported Evaluations}

Participants reported a preference for the Black actor over the White actor, $t \mathrm{~s}(217$, 229) $=-8.57,-5.41, p \mathrm{~s}<.001, d \mathrm{~s}=-0.58,-0.36, B F_{10}>1,000$.

In Study 26, participants evaluated the photos of the Black actor (Eddie Murphy) more favorably than the photos of the White actor (Ben Affleck), $t(217)=-8.58, p<.001, d=$ $-0.58, B F_{10}>1,000$. In Study 27 , there was no difference between the average evaluations of the photos of the Black actor (Samuel L. Jackson) and the White actor (George Clooney) $t(229)=-1.07, p<.285, d=-0.07, B F_{10}=0.130($ the Bayes factor indicated moderate evidence for no difference).

Participants reported a slight preference for White people over Black people, $t \mathrm{~s}(217$, 229) $=2.89,3.46, p \mathrm{~s}=.004,<.001, d \mathrm{~s}=0.19,0.23, B F_{10}=4.28,23.80$. This difference from the no preference reported by participants in Studies 1-19 could be attributed to the different populations from which the participants were sampled (Project Implicit might attract more liberal participants than Prolific). This slight pro-White preference relative to the pro-Black actor preference increases the likelihood that the reported preference for the Black actor was the result of the individuating information the participants have learned about the actors. 


\section{IATs}

Participants' IATs suggested a preference for the White actor over the Black actor, $t s(217,229)=6.25,8.14, p s<.001, d s=0.42,0.54, B F_{10}>1,000$, a preference for White people over Black people, $\left.t s(217,229)=14.20,12.50, p s<.001, d s=0.96,0.82, B F_{10}\right\rangle$ 1,000 , and a preference for flowers over insects, $t s(217,229)=23.80,27.20, p s<.001, d s=$ $1.61,1.79, B F_{10}>1,000$.

In the online supplement, we report an exploration of the relation between the IAT and self-reported targets and race preference scores, as in Studies 1-17. Similar to what we found in Studies 1-17, the IAT was related to self-reported target evaluation, even after controlling for self-reported group evaluations, again indicating that the IAT was sensitive to individuating information, and not just to group information.

\section{Relations between evaluations of the individuals and evaluations of their social groups}

Table 7 presents the correlations between the measures in Studies 26-27.

Descriptively, in both studies, the relation between the R-IAT and the A-IAT was stronger than the relation between the R-IAT and self-reported actors preference and the relation between the A-IAT and self-reported race preference. Conversely, the relation between selfreported preference between actors and the self-reported preference between the social groups was stronger than the relation between self-reported actors preference and the R-IAT and the relation between self-reported social groups preference and the A-IAT.

For statistical testing of this pattern, we conducted regression analyses, within a framework of Structural Equation Modeling (SEM) to account for measurement error (Buttrick et al., 2020; Kurdi et al., 2019; Westfall \& Yarkoni, 2016). We used the R package lavaan (version 0.6-3, Rosseel, 2012) to conduct these tests. We conducted two multiple regression analysis: one with the R-IAT scores as the outcome variable, and one with the selfreported preference between the social groups as the outcome variable. We used three 
predictors in both analyses: the self-reported preference between the actors, the A-IAT, and the FI-IAT. In the R-IAT analysis, we entered the FI-IAT to control for the IAT's method variance. Thus, the unique shared variance between the A-IAT and the R-IAT could not be attributed to method variance because that variance would have been shared with the FI-IAT (Uhlmann et al., 2006). Figures S3-S4 in the online supplement show the model diagrams. We also included the FI-IAT in the model that predicted self-reported preference, to rule out the possibility that the absence of that predictor is the reason for any discrepancy we would find between the model that predicted the R-IAT and the model that predicted the self-reported preference. In the online supplement, we report an alternative statistical technique hierarchical regression - with similar conclusions.

For sufficient statistical power, we combined the samples of Studies 26 and 27, and added the study as a predictor of each measure to control for variance resulting from differences between the pair of actors used in each study. We did not include the photo-rating preference score in these analyses, due to its high correlation with the self-reported preference between the actors $(r=.613)$. Including the photo preference score in the analyses did not change the conclusions, only decreased the $\beta$ weight of the self-reported preference between the actors when predicting the self-reported preference between the social groups. The results of the regression analyses (Table 8) confirmed that the R-IAT was more strongly related to the A-IAT than to self-reported preference between the actors. Conversely, the self-reported preference between the social groups was significantly related to the self-reported preference but not to the A-IAT, although the difference between these relation, was not statistically significant $(p=.068)$. 


\section{Table 7}

Studies 26-27: Pearson correlations

\begin{tabular}{|c|c|c|c|c|c|c|}
\hline & & Self-report actors & Self-report race & A-IAT & R-IAT & FI-IAT \\
\hline \multirow[t]{2}{*}{ Self-report actors } & $r$ & & $.210, .244$ & $0.284, .173$ & $0.050, .098$ & $-0.004, .069$ \\
\hline & $p$ & & $.002,<.001$ & $<.001, .009$ & $0.466, .140$ & $0.954, .294$ \\
\hline \multirow[t]{2}{*}{ Self-report race } & $r$ & 0.228 & & $0.150, .123$ & $.222, .332$ & $.010, .084$ \\
\hline & $p$ & $<.001$ & & $0.027, .063$ & $<.001$ & $.886, .203$ \\
\hline \multirow[t]{2}{*}{ A-IAT } & $r$ & 0.232 & 0.137 & & $.333, .309$ & $.119, .054$ \\
\hline & $p$ & $<.001$ & 0.004 & & $<.001$ & $.080, .413$ \\
\hline \multirow[t]{2}{*}{ R-IAT } & $r$ & 0.065 & 0.277 & 0.316 & & $.141, .194$ \\
\hline & $p$ & 0.167 & $<.001$ & $<.001$ & & $.037, .003$ \\
\hline \multirow[t]{2}{*}{ FI-IAT } & $r$ & 0.036 & 0.048 & 0.089 & 0.165 & \\
\hline & $p$ & 0.45 & 0.308 & 0.06 & $<.001$ & \\
\hline
\end{tabular}

Note. A-IAT $=$ Actors IAT, R-IAT $=$ Race IAT, FI-IAT $=$ Flowers-Insects IAT. Below the diagonal: the correlation within the samples of both studies. Above the diagonal: the correlations for Study 26, and for Study 27, separately; Ns = 448 (combined), 218 (Study 26), 230 (Study 27). In bold: The relations with preference between the social groups. 
Table 8

Studies 26-27 (combined data): Standardized regression coefficients for the prediction of group (race) preference by self-reported actors preference, Actors IAT (A-IAT), and Flowers-Insects IAT (FI-IAT)

\begin{tabular}{|c|c|c|c|c|c|c|c|c|c|}
\hline \multirow[b]{2}{*}{ Predictor } & \multirow[b]{2}{*}{ Estimation } & \multirow[b]{2}{*}{$S E$} & \multicolumn{2}{|c|}{$\begin{array}{l}\text { Test of the difference } \\
\text { from zero }\end{array}$} & \multirow[b]{2}{*}{$\begin{array}{l}\text { Standard } \\
\text { estimation }\end{array}$} & \multicolumn{2}{|c|}{$95 \% \mathrm{CI}$} & \multicolumn{2}{|c|}{$\begin{array}{l}\text { Self-report-IAT } \\
\text { comparison }^{\text {a }}\end{array}$} \\
\hline & & & $Z$ & $p$ & & LB & UB & $Z$ & $p$ \\
\hline \multicolumn{10}{|c|}{$\begin{array}{l}\text { Model 1: predicting self-reported } \\
\text { race preference }\end{array}$} \\
\hline Self-reported actors preference & .265 & .065 & 4.053 & $<.001$ & .255 & .138 & .37 & 1.820 & .068 \\
\hline \multicolumn{10}{|l|}{ Model 2: predicting R-IAT } \\
\hline Self-reported actors preference & -.020 & .071 & -0.283 & .776 & -.018 & -.14 & .10 & -3.864 & $<.001$ \\
\hline A-IAT & .435 & .078 & 5.520 & $<.001$ & .388 & .26 & .50 & & \\
\hline FI-IAT & 0.204 & .065 & 3.104 & .002 & .182 & .07 & .29 & & \\
\hline
\end{tabular}

Note . A-IAT $=$ Actors IAT, R-IAT $=$ Race IAT, FI-IAT $=$ Flowers-Insects IAT. The model removes the variance originating from the inclusion of different studies, and also controls for common-method variance of the IAT measure by including the FI-IAT. SE = standard error; 95\% CI = 95\% confidence interval; $\mathrm{LB}=$ Lower bound; $\mathrm{UB}=$ Upper bound. ${ }^{\mathrm{a}}$ Testing whether the $\beta$ coefficients for self-reported preference between the actors and A-IAT scores were significantly different (by comparing a model that forces equal coefficients to the model presented in the table, which does not force that constraint). 


\section{Discussion}

We replicated our previous results with a different sample and using a direct measure of self-reported preference. We found evidence compatible with the hypothesis that the reason for the discrepancy is the automatic evaluation of the individuals' social groups: the preference for White people over Black people in a White people/Black people IAT was much stronger than the self-reported preference. Importantly, the scores of that IAT were more strongly related to scores on the IAT that compared the White and the Black actors than to the self-reported preference between the actors. The self-reported preference between the actors was more strongly related to self-reported preference between the groups than to the scores on the White people/Black people IAT.

\section{Studies 28-29: The Effect of Individuating Information on Automatic Evaluation}

The results of Studies 26-27 are compatible with an effect of group membership on the judgment of well-known individuals: the effect of preference between the dominant and the stigmatized groups on the preference between their members. Because participants did not report a preference for the stigmatized group over the dominant group, we attribute their self-reported preference for the member of the stigmatized group over the member of the dominant group to individuating information. Have we found any evidence that automatic judgment was sensitive to individuating information? On Studies 1-17, the different actors' stimuli yielded considerable variance in the effect-size of the preferences suggested by the IAT $(d s=-0.22-0.61)$. This variance may reflect variance in the individuating information of the targets. For example, it seems clear from Figure 1, that Will Smith was the most liked Black target, as reflected in the self-reported preference and the IAT scores in studies that used him as the target Black individual, in comparison to the other studies. Further, in Studies 26-27, the pro-White 
preference suggested by the average score of the Race IAT $(d s=0.97,0.81)$ was much larger than the preference between the actors suggested by the average score of the Actors IAT $(d s=$ $0.41,054)$. This difference could be attributed to the more favorable individuating information about the Black target, in comparison to the White target (as evident by the self-reported preference for the Black target over the White target, despite a (small) self-reported preference for the dominant group over the stigmatized group).

In our final studies, we directly tested the effect of individuating information on an IAT developed to measure the preference between the two familiar group members. Participants first observed pairs of actors (one member of the dominant group and one member of the stigmatized group within each pair) and reported whom they prefer within each pair. We then used the IAT to measure their evaluation of one of these pairs. In the pro-dominant condition, we selected a pair in which the member of the dominant group was self-reportedly preferred over the member of the stigmatized group. In the pro-stigmatized condition, we selected a pair in which the member of the stigmatized group was self-reportedly preferred over the member of the dominant group. If the IAT scores would suggest a larger pro-dominant preference in the pro-dominant than in the pro-stigmatized condition, that would be compatible with the possibility that individuating information influenced the automatic evaluation.

\section{Method}

Participants

The details about the participants appear in Table 1.

\section{Measures and Procedure}

We presented participants with eight White and eight Black movie actors (Study 28), or eight young and eight old movie actors (Study 29), see Table S13 in the online supplement for 
the list of stimuli. Participants first rated their familiarity with the set 16 actors (possible answers were: I don't know who this person is, I know a bit about this person, and I know much about this person). After excluding actors that participants reported not knowing, we presented pairs of actors (one member of the dominant group and one member of the stigmatized group within each pair) and instructed participants to choose the actor they prefer.

In the pro-stigmatized condition, we selected for each participant a pair of actors in which the participant reported preferring the Black (old) actor. In the pro-dominant condition, we selected, for each participant, a pair in which the White (young) actor was preferred over the Black (old) actor. If there was more than one pair that fit that requirement, one of these pairs was selected randomly.

IAT. The characteristics and data preparation for the IAT were the same as in our previous studies.

Self-reported evaluation. At the end of the study, participants rated their preference between the actors of the selected pair. This measure served as a manipulation check. The questions were: Whom do you like more, [Name of Stigmatizedactor] or [Name of dominant actor]? Are your thoughts more positive toward [Name of Stigmatized actor] or [Name of dominant actor]? Are your feelings more positive toward [Name of non-dominant actor] or [Name of dominant actor]? Answers ranged from 1 (e.g., I like [Name of Stigmatized actor] extremely more than [Name of dominant actor]) to 7 (e.g., I like [Name of dominant actor] extremely more than [Name of Stigmatized actor]). We averaged the responses to the three items to a single score, with higher values indicating a stronger preference of the White (young) actor over the Black (old) actor. 


\section{Results}

Table 9 presents the descriptive statistics for the IAT and self-reported preference between the actors, as a function of the selection rule (i.e., experiment condition), and the social group (race, age).

\section{Table 9}

Studies 28-29: Descriptive statistics for each measure for each target selection condition and social group

\begin{tabular}{llllllll}
\hline Study & Target selection & Judgment task & Measure & $N$ & $M$ & $S D$ & $\alpha$ \\
& condition & & & & & \\
& & & & & & & \\
\hline 28 & Pro-stigmatized & Race & IAT & 216 & -0.01 & 0.39 & 0.78 \\
& Pro-dominant & Race & IAT & 198 & $0.10^{* * *}$ & 0.42 & 0.84 \\
& Pro-stigmatized & Race & Self-report & 216 & $-1.27^{* * *}$ & 1.01 & 0.91 \\
& Pro-dominant & Race & Self-report & 197 & $0.21^{* * *}$ & 0.90 & 0.89 \\
& Pro-stigmatized & Age & IAT & 178 & 0.01 & 0.36 & 0.73 \\
& Pro-dominant & Age & IAT & 181 & $0.20^{* * *}$ & 0.37 & 0.79 \\
& Pro-stigmatized & Age & Self-report & 178 & $-0.70^{* * *}$ & 1.02 & 0.89
\end{tabular}

Note . Pro-stigmatized $=$ We selected targets such that, according to the initial self-reported rating, the Black target was preferred over the White target; Pro-dominant $=$ We selected targets such that, according to the initial self-reported rating, the White target was preferred over the Black target. Positive values indicate stronger preference for the member of the dominant group (White / young). Asterisks indicate comparison of the mean to zero (no preference): *** $p<$ .001 . 


\section{The discrepancy between the IAT and self-report}

As shown in Table 9, in both studies, we found a stronger pro-dominant preference in the IAT than in the self-report. The overall IAT preference scores suggested a pro-dominant bias for both race (Study 28) and age (Study 29) targets; Race: $M=0.04(0.41), t(413)=1.98, p=.049, d$ $=0.10, B F_{10}=0.38$; Age: $M=0.10(0.37), t(358)=5.45, p<.001, d=0.29, B F_{10}>1,000$. The overall self-report preference scores showed a pro-stigmatized bias, for race targets (Study 28): $M=-0.56(1.21), t(412)=-9.36, p<.001, d=-0.46, B F_{10}>1,000$, but not for age targets (Study 29): $M=-0.01(1.21), t(358)=-0.15, p=.874, d=-0.00, B F_{10}=0.06$.

The preference scores were not consistently different from zero probably because we examined them in this section beyond the stimulus selection condition. Therefore, we performed another test of the discrepancy between the measures. In this test, we computed the difference between the effect-sizes of the IAT and self-report scores, after adjusting the effect-sizes for each measure's reliability (this procedure verifies that the obtained difference in effect sizes does not stem from low reliability of one measure relative to the other, see Baugh, 2002; Gawronski et al., in press) $)^{2}$. To test whether the difference between the two effect-sizes is significant, we computed the $95 \%$ confidence-intervals around that difference using a bootstrapping procedure, with the R package boot (version 1.3-22, Canty \& Ripley, 2019). The difference between selfreport and IAT scores was significant for both Race targets (Study 28): diffIIA-Self-report $=0.585$ [0.45, 0.71], and Age targets (Study 29): diff IAT-Self-report $=0.337$ [0.21, 0.45].

\section{The effect of individuation}

Self-reported evaluation. As expected from our stimulus selection manipulation, participants reported a preference for the member of the stigmatized group over the member of

\footnotetext{
${ }^{2}$ We thank Mattan S. Ben-Shachar for his helpful recommendation to use this statistical procedure.
} 
the dominant group in the Pro-stigmatized condition, and the opposite preference in Prodominant condition. That difference was large and highly significant. In Study $28, t(411)=$ 15.72, $p<.001, d=1.55, B F_{10}>1,000 ;$ In Study $29, t(357)=13.11, p<.001, d=1.39, B F_{10}>$ 1,000 .

IAT. The crucial test in the present studies was the effect of the manipulation on the IAT scores. In both studies, the pro-dominant preference on the IAT was stronger under the Prodominant condition than under the Pro-stigmatized condition. In Study $28, t(412)=3.05, p=$ $.002, d=0.30, B F_{10}=9.47 ;$ In Study $29, t(357)=4.86, p<.001, d=0.51, B F_{10}>1,000$.

\section{Discussion}

We found that the IAT scores suggested a stronger pro-dominant preference when participants judged a pair of individuals in which the member of the dominant group was selfreportedly preferred over the member of the stigmatized group, than when participants judged a pair in which the member of the stigmatized group was self-reportedly preferred over the member of the dominant group. Because the group membership was the same in both conditions, we attribute this difference to the individuating information about the targets. Therefore, these results suggest that the individuating information about the targets influenced automatic preference.

\section{General Discussion}

Across 29 studies, we used self-report measures and indirect measures of evaluation to examine the deliberate and automatic evaluation of well-known individual group members. We found a discrepancy between self-report measures and indirect measures of the evaluations of well-known individual group members. Participants reported a preference for members of the stigmatized group (Black famous people and old famous people) over members of the dominant 
group (White famous people and young famous people), but the preference suggested by the indirect measure was often reversed, or at least much smaller than the self-reported preference. These findings were consistent across various stimuli and across different measures and samples. In Studies 1-23, we found a discrepancy between self-report and indirect measures across various famous actors, from two social groups (race: White/Black, age: Young/Old), with participants from two different countries (USA, Israel), using two different indirect measures (IAT, EPT), and across different formats of self-report measures.

In Studies 24-25, we found that hiding the visual characteristics of the group decreased the indirectly measured preference for the member of the dominant group over the member of the stigmatized group, but had no effect on the self-reported preference between the individuals. In Studies 26-27, individual differences in the indirectly measured preference between the social groups was predicted by individual differences in the indirectly measured preference, but not the self-reported preference between the individuals. Conversely, individual differences in the selfreported group preference were predicted by individual differences in the self-reported, but not the indirectly measured preference between the individuals. In Studies 28-29, we found that both individuating information and group information influenced the indirectly measured preference.

The results of the present research provide a powerful demonstration of the grip that social group membership has on the evaluation of individuals. The results suggest that the automatic evaluation of individuals from a stigmatized group, often reflects the automatic evaluation of the social group, even when the individuals have been well-known to the perceiver for quite some time. These results are valuable evidence of the ubiquity of automatic prejudice ${ }^{3}$.

\footnotetext{
${ }^{3}$ Note that when there was a substantial deliberate preference for the stigmatized group member and no automatic preference between the targets, these results still reflected prejudice because the reason for that discrepancy was an effect of the target's group membership on the automatic evaluation of the target.
} 
To date, research on automatic prejudice has focused on the evaluation of groups (e.g., Old people) and novel people (e.g., an unknown Black person). However, people often evaluate individuals that they have known for a few days, weeks, or years. Our results suggest that even under those circumstances - despite long-held knowledge idiosyncratic to the specific target person - the negative automatic evaluation of the target's stigmatized social group would negatively bias the automatic evaluation of the target person, relative to the deliberate evaluation of that person.

\section{Theoretical Implications}

\section{Long-Held Non-Prejudiced Deliberate Evaluation Does Not Eliminate Automatic Prejudice}

Based on previous theory and evidence (Fazio et al., 1986; Logan, 1988; Nosek, 2005;

Nosek, Greenwald, et al., 2007), it seemed plausible that people's long-held knowledge about the target individuals would increase the accessibility of their deliberate evaluation, which in turn might increase the similarity between the automatic and deliberate evaluations. Yet, we found that the preference for the dominant group over the stigmatized group still dominated the results of the indirect measures we used to assess the automatic preference between the targets. The automatic preference for the member of the dominant group over the member of the stigmatized group might suggest that long-term exposure to the individuals also encoded group-related evaluations that repeatedly occurred together with the evaluation of the individuating information about the actors. That is, the group evaluation was integrated into the evaluation associated with the individual targets. Another possibility is that although individuating positive information was well-encoded without the group evaluation, it did not stop the automatic activation of the evaluation of the targets' group characteristics (e.g., Black skin tone, or wrinkles), which had a large influence on the overall automatic evaluation of the individuals. 
We tested the possible reasons for an automatic preference in favor of the member of the dominant group by manipulating the exposure to visual group characteristics in Studies 24-25. The targets appeared either only by name (visual characteristics of the groups were absent) or visually in photos (visual characteristics of the groups were present). Had the indirect measure showed, in Studies 24-25, the same pro-dominant preference in both conditions, this result would have been compatible with the possibility that the judgment of the group membership has been integrated into the evaluative representation of the targets. Conversely, had the indirect measure showed the same a preference as self-reported preference when the target individuals appeared only by names (i.e., favoring the member of the stigmatized group), that result would have been compatible with the possibility that the automatically activated evaluative representation of the targets was the same as the deliberate evaluation. In that case, the discrepancy between indirect measures and self-report when the targets appear in photos could have been attributed in full to an automatic evaluative reaction to the visual group characteristics of the targets (i.e., skin-tone and facial features).

The results of Studies 24-25 supported both reasons for the preference for the member of the dominant group over the member of the stigmatized group on the indirect measures. In the name condition (when visual characteristics of the group were absent), there was no preference on the indirect measure for any of the individuals. In other words, the preference for the member of the dominant group over the member of the stigmatized group disappeared but did not reverse. The lack of preference for the member of the stigmatized group on the indirect measure when the targets appeared only by names, despite self-reported preference for that member, might suggest that the judgment of the group has been integrated into the evaluative representation of the individual. The decrease in the pro-dominant preference (i.e., in comparison to the photos 
condition), however, suggests that automatic evaluative reaction to the group's visual characteristic does contribute to the pro-dominant preference that the indirect measures showed in all of our studies. In other words, the results of Studies 24-25 are compatible with the possibility that the group judgment is integrated into the automatic reaction to the target individuals, and is also automatically activated when perceiving the target with the group characteristics. The results of the present research might reflect two effects of the group membership on the automatic judgment of individual targets: one is an effect of the group membership on the encoding of an evaluative representation of the target, and the other is an effect of the group membership on the evaluative reaction to the target that occurs upon expression, following the exposure to visual characteristics of the group.

Why did using stimuli that included visual group-related features increase the preference for the member of the dominant group on the indirect measure of evaluation? One possible reason could be the activation of valence following the categorization of the targets' face to social groups (e.g., the identification of the targets as belonging to the groups young people and old people). Indeed, there is evidence that people are extremely fast in categorizing faces to social groups (Ito \& Urland, 2003, 2005; Quinn et al., 2010). Stereotypes and prejudice are also activated fast and spontaneously (Blair \& Banaji, 1996; Bodenhausen \& Macrae, 1998; Fazio et al., 1995; Kunda et al., 2002; Kunda \& Spencer, 2003), following the exposure to a cue that signals group-membership. Thus, the exposure to a target's face might activate prejudice and stereotypes due to the categorization of that face to a social group.

A second possible reason for the increase in the effect of group membership on the preference suggested by indirect measure when using visual stimuli is that visual characteristics of certain social groups might have become imbued with the valence of the group. Research has 
shown that (negative) valence is activated in response to the exposure to a target's face independently of group categorization (Livingston \& Brewer, 2002). Specifically, following multiple events of pairing (negative) evaluation toward the social group with faces that belong to that group (e.g., Black people), facial features that are considered prototypical of the group accrue the valence of the group. As a result, exposure to faces with relatively prototypical grouprelated facial features can activate prejudice even without group categorization. The effect of group-membership upon exposure to visual group-related features could be explained by any of

these processes (i.e., category-based and feature-based effect of visual group-related characteristics), or even by the operation of both. The present evidence is compatible with all these possibilities.

\section{The Influence of Group Membership and Individuating Information on the Targets'}

\section{Evaluation}

The results of Studies 24-25 provide strong support for our assumption that the reason for the discrepancy between self-report and indirect measures of evaluation of well-known individuals is the effect of group membership: Exposure to the visual characteristics of the group increased the pro-dominant preference on the indirect measure and therefore increased the discrepancy between the indirectly measured preference and the self-reported preferences. The lack of evidence for an effect of the manipulation of visual characteristics (i.e., present vs. absent) on self-reported evaluation might suggest that automatic evaluation is more sensitive to group membership than deliberate evaluation is. That finding is compatible with previous findings that automatic evaluation is sensitive to manipulations of temporary accessibility of specific features of the targets (Spruyt et al., 2009). Further, automatic evaluations (or automatic processes more generally) are more susceptible to temporary accessibility of features than 
deliberate evaluations, apparently because people can control attention allocation better when engaging in deliberate processes (Van Dessel et al., 2016, 2017).

The possibility that, relatively to individuating information, group membership has a stronger effect on automatic than on deliberate evaluation is, however, only suggestive because it is based on a null effect on self-reported evaluation (somewhat bolstered by the Bayesian analysis). Further, our results provide clear evidence that the self-reported preference between the individuals was related to the self-reported preference between their social groups. Therefore, although our studies found tentative evidence that automatic evaluation is more sensitive to group membership compared with deliberate evaluation, our results definitely do not rule out an effect of group membership on deliberate evaluation. In other words, we found evidence that both deliberate and automatic evaluations are sensitive to (i.e., prejudiced by) the target's group membership.

If both deliberate and automatic evaluations of well-known individuals are sensitive to (deliberate and automatic, respectively) evaluations of their social groups, the reason for the discrepancy that we found between automatic and deliberate evaluation of the individuals is straightforward: the automatic preference for the dominant group over the stigmatized group is much stronger than the deliberate preference between the groups. The results of Studies 26-27 support that account: participants reported a slight preference for White people over Black people $(d s=0.20,0.23)$ and showed a strong preference for White people over Black people on the R-IAT ( $d \mathrm{~s}=1.00,0.83$ ). Further support to that account comes from Studies 26-27's finding that self-reported group preference was related to the self-reported preference between the individuals, whereas the group preference measured with the R-IAT was related to the preference between the individuals that was measured with the A-IAT. 
Our results do not suggest that individuating information about well-known people does not influence automatic evaluation. The influence of idiosyncratic information about the individuals is a probable reason for the variability in preferences found with the same indirect measures but different target individuals across studies (see Figure 1). Further, in Studies 1-17 and 26-27, the evaluation of the individuals measured with the IAT was related to self-reported evaluation of the individuals, beyond its relation to self-reported evaluation of the groups. Moreover, in Studies 26-27, the preference between the groups on the R-IAT $(d s=0.964,0.825)$ was larger than the preference between the actors on the A-IAT $(d \mathrm{~s}=0.423,0.537)$. A likely reason for that difference is people's individuating knowledge about each actor. Individuating information is also a main possible explanation for the difference between self-reported preference in Studies 26-27 for White people over Black people $(d \mathrm{~s}=0.195,0.228)$ and the selfreported preferences for the Black actor over the White actor $(d \mathrm{~s}=-0.580,-0.357)$. The most direct evidence for the influence of individuating information about well-known people on automatic evaluation comes from Studies 28-29, that directly manipulated the individuating information (but not the group information), and found a difference in the IAT scores as a function of that individuating information. Yet, individuating information was not strong enough to outweigh the effect of group information.

As explained in the introduction, it is not easy to estimate the relative influence of individuating information and group membership on each type of evaluation. For such an estimation, we will need to estimate the evaluative value of the individuating information about each target, regardless of their group membership. Because there is no White Eddie Murphy or Black George Clooney, this is quite impossible in the present research. In fact, we do not have information about the content of the individuating information people have gathered about these 
popular individuals. We assumed that, over time, people have gathered some idiosyncratic individuating information about the popular individuals, such as performing capabilities, humor, and apparent trustworthiness. However, we did not design our studies to investigate the exact individuating information our participants actually have. We tolerated these limitations in the present research in favor of gaining high ecological validity by using real-life targets.

Self-presentation motives. One possible reason why the deliberate non-prejudiced evaluation did not automatize and spread to the automatic evaluation is that the deliberate evaluation is also prejudiced, but the self-report fails to detect that because people prefer to present themselves as non-prejudiced. There is some evidence against that possibility. First, participants reported no preference between the groups (Studies 1-17, 24-25) or a slight preference for the dominant group (Studies 26-27), but a clear preference for the member of the non-dominant, stigmatized, group in all those studies. It is unclear why the motivation to appear non-biased would influence the self-reported evaluation of the individuals more than the selfreported evaluation of the social groups. The opposite seems more reasonable because people can always explain their preference for a White actor over a Black actor with reasons other than their group membership. Further, we found the same discrepancy in Studies 21 and 23. Our intuition is that appearing non-prejudiced toward Old people is not a strong motive among Israelis, especially when judging famous movie stars and musicians. Still, further research could test more directly whether the motivation to appear non-biased is one of the reasons for the discrepancy found in the present research by measuring or manipulating that motivation, or by using social groups that people are not ashamed to favor, such as women over men (Rudman \& Goodwin, 2004). 


\section{Limitations and Future Directions}

\section{Familiarity with the Target Actors}

Although we assumed that participants acquired the individuating information about the actors long before the study, and that they were repeatedly exposed to individuating information about the target individuals for a long period of time, we did not control for the amount of information that participants acquired, nor for the acquisition time, or for the content of individuating information that each participant stored about the actors. We did, however, verify that the results replicate when all participants report familiarity with the two actors they evaluated (Studies 18-29). Testing our conclusions under more controlled conditions would be informative (although challenging, as we previously alluded). Further, the well-known individuals were popular movie actors and musicians. Future research could test whether our results generalize to individuals that people know from their close environment (e.g., a workcolleague or a close friend). Face-to-face personal interactions and media coverage might differ in their influence on the effect of group membership on the evaluation of known targets.

There are two main differences between the present research and previous research about the effect of individuating information on automatic judgment of members of stigmatized groups (Cao \& Banaji, 2016; Rubinstein et al., 2018). First, previous research has not tested favorability judgment, only stereotypes - trait judgment (about intelligence, Rubinstein et al., 2018) and occupation judgment (Cao \& Banaji, 2016). Second, previous research has tested judgment of novel targets, introduced to the participant only shortly before the evaluation measurement. The previous research found evidence for automatic stereotypes, although that evidence was almost completely eliminated when the individuating information was extensive and diagnostic. Our results suggest that prejudice in favorability judgment is not easily diminished even when the 
individuating information is long-held and is clearly strong enough to induce deliberate preference for the member of the stigmatized group over the member of the dominant group. Yet, there are a number of important cases missing from an exhaustive incremental research on the effect of individuating information on automatic prejudice. First, there has not been research yet about the effect of individuating information on the favorability judgment of novel members of a stigmatized group and a dominant group. A second missing piece of the puzzle is the effect of long-held individuating knowledge about automatic trait judgment (i.e., automatic stereotypes). Lastly, it would also be interesting to test whether there is a larger discrepancy when the groups are differentiated by clear visual cues (e.g., race, age), compared with groups for which the cues are more ambiguous (e.g., sexual orientation, religion). Ongoing work in our lab is currently investigating those cases.

\section{The Inference about Automatic Evaluation from Indirect Measures}

A particularly promising feature of the present findings is that discrepancy from selfreported evaluation was found with two different indirect measures. We are unaware of any other study that documented such a discrepancy with two different indirect measures. Still, it would be important to search for other behaviors that would reflect the automatic evaluation more than the deliberate evaluation. For instance, if the automatic preference between well-known individuals would predict people's choice between job candidates, especially if done under suboptimal conditions (e.g., when cognitively taxed), that would increase the confidence that the present findings tap into an important theoretical construct that influences consequential behavior, beyond performance in computerized sorting tasks.

In the introduction, we reviewed evidence that suggests that the IAT and the EPT capture evaluative processes that, relatively to self-report, are faster, more unintentional and more 
effortless than the processes that influence self-report questionnaires (De Houwer et al., 2009). However, we also reviewed evidence that both measures are not sensitive only to automatic evaluative process. Because of the doubt about the construct(s) captured by any indirect measure that was developed to measure automatic judgment, we were careful to test our questions with two different indirect measures. At present, there is no evidence for a non-evaluative factor that explains the outcomes of both the IAT and EPT. Moreover, we tested our questions using multiple different stimuli, two distinct attitude domains, and samples from two different cultures. The consistency of the results across different conceptual replications is a constraint on any alternative account that would attribute the results to constructs other than those that we attempted to test (i.e., deliberate and automatic judgment). On the other hand, the theoretical and empirical work that has doubted the usefulness of umbrella term automatic judgment and the validity of the measures that we used here (Brown-Iannuzzi et al., 2019; Greenwald \& Nosek, 2001; McFarland \& Crouch, 2002; Mierke \& Klauer, 2003; Olson \& Fazio, 2004; Steffens, 2004; Teige-Mocigemba \& Klauer, 2008; Uhlmann et al., 2006; Unkelbach \& Fiedler, 2020) provide grounds to doubt our interpretation of the present findings.

\section{Conclusion}

The measurement of evaluation with indirect measures has facilitated the empirical investigation of the long-held notion that despite people's best (reported) intentions, ingroup favoritism and prejudice against disadvantaged groups persist, at least automatically. Nevertheless, one could still hope that when the target individuals are well-known, their group membership is inconsequential for judgment. The present findings suggest that this is not the case: on indirect measures, the preference between well-known stigmatized and dominant group 
members in our studies was in line with the evaluation of their group membership (race, age).

Perhaps even well-known individuals are not free from the burdens of automatic prejudice. 


\section{References}

Ach, N. (1935). Analyse des Willens. [Analysis of will.]. Handbuch Der Biologischen Arbeitsmethoden, Abt. 6, Teil E, 460-460.

Allport, G. W. (1954). The nature of prejudice. Addison-Wesley.

Amodio, D. M. (2019). Social Cognition 2.0: An interactive memory systems account. Trends in Cognitive Sciences, 23(1), 21-33. https://doi.org/10.1016/j.tics.2018.10.002

Amodio, D. M., \& Devine, P. G. (2006). Stereotyping and evaluation in implicit race bias: Evidence for independent constructs and unique effects on behavior. Journal of Personality and Social Psychology, 91(4), 652-661. https://doi.org/10.1037/00223514.91.4.652

Amodio, D. M., \& Mendoza, S. A. (2010). Implicit intergroup bias: Cognitive, affective, and motivational underpinnings. In Handbook of implicit social cognition: Measurement, theory, and applications. (pp. 353-374). The Guilford Press.

Asendorpf, J. B., Banse, R., \& Mücke, D. (2002). Double dissociation between implicit and explicit personality self-concept: The case of shy behavior. Journal of Personality and Social Psychology, 83(2), 380-393. https://doi.org/10.1037/0022-3514.83.2.380

Axt, J. R., Bar-Anan, Y., \& Vianello, M. (2020). The relation between evaluation and racial categorization of emotional faces. Social Psychological and Personality Science, 11(2), 196-206. https://doi.org/10.1177/1948550619848000

Bar-Anan, Y., \& Nosek, B. A. (2014). A comparative investigation of seven indirect attitude measures. Behavior Research Methods, 46(3), 668-688. https://doi.org/10.3758/s13428013-0410-6 
Bar-Anan, Y., Nosek, B. A., \& Vianello, M. (2009). The Sorting Paired Features task: A measure of association strengths. Experimental Psychology, 56(5), 329-343. https://doi.org/10.1027/1618-3169.56.5.329

Bargh, J. (1994). The Four Horsemen of Automaticity: Awareness, Efficiency, Intentions and Control. In R. Wyer \& T. Srull (Eds.), Handbook of Social Cognition (p. 1040). Lawrence Erlbaum.

Baugh, F. (2002). Correcting Effect Sizes for Score Reliability: A Reminder that Measurement and Substantive Issues are Linked Inextricably. Educational and Psychological Measurement, 62(2), 254-263. https://doi.org/10.1177/0013164402062002004

Blair, I. V., \& Banaji, M. R. (1996). Automatic and controlled processes in stereotype priming. Journal of Personality and Social Psychology, 70(6), 1142-1163. https://doi.org/10.1037/0022-3514.70.6.1142

Blair, I. V., Ma, J. E., \& Lenton, A. P. (2001). Imagining Stereotypes Away: The Moderation of Implicit Stereotypes Through Mental Imagery. Journal of Personality and Social Psychology, 81(5), 828-841.

Bodenhausen, G. V., Kang, S. K., \& Peery, D. (2012). Social Categorization and the Perception of Social Groups. In The SAGE Handbook of Social Cognition The SAGE handbook of social cognition (pp. 311-329). SAGE Publications Ltd. https://doi.org/10.4135/9781446247631.n16

Bodenhausen, G. V., \& Macrae, C. N. (1998). Stereotype activation and inhibition. In Stereotype activation and inhibition. (pp. 1-52). Lawrence Erlbaum Associates Publishers.

Borenstein, M., Hedges, L. V., Higgins, J. P. T., \& Rothstein, H. R. (2009). Introduction to Meta-Analysis. Chichester, UK: Wiley. 
Brewer, M. (1988). A dual process model of impression formation. TK Srull, RS Wyer, Jr., eds. Advances in Social Cognition, Vol. 1. Erlbaum, Hillsdale, NJ.

Brewer, M. B., \& Feinstein, A. S. H. (1999). Dual processes in the cognitive representation of persons and social categories. In Dual-process theories in social psychology. (pp. 255270). Guilford Press.

Brooks, J. A., \& Freeman, J. B. (2018). Psychology and neuroscience of person perception. In J. T. Wixted (Ed.), Stevens' Handbook of Experimental Psychology and Cognitive Neuroscience (pp. 1-36). John Wiley \& Sons, Inc. https://doi.org/10.1002/9781119170174.epcn413

Brown-Iannuzzi, J. L., Cooley, E., McKee, S. E., \& Hyden, C. (2019). Wealthy Whites and poor Blacks: Implicit associations between racial groups and wealth predict explicit opposition toward helping the poor. Journal of Experimental Social Psychology, 82, 26-34.

Buttrick, N., Axt, J., Ebersole, C. R., \& Huband, J. (2020). Re-assessing the incremental predictive validity of Implicit Association Tests. Journal of Experimental Social Psychology, 88, 103941.

Cameron, C. D., Brown-Iannuzzi, J. L., \& Payne, B. K. (2012). Sequential priming measures of implicit social cognition: A meta-analysis of associations with behavior and explicit attitudes. Personality and Social Psychology Review, 16(4), 330-350.

Canty, A., \& Ripley, B. (2019). boot: Bootstrap R (S-Plus) Functions. (R package version 1.322.) [Computer software].

Cao, J., \& Banaji, M. R. (2016). The base rate principle and the fairness principle in social judgment. Proceedings of the National Academy of Sciences, 113(27), 7475-7480. https://doi.org/10.1073/pnas.1524268113 
Castelli, L., Zogmaister, C., Smith, E. R., \& Arcuri, L. (2004). On the automatic evaluation of social exemplars. Journal of Personality and Social Psychology, 86(3), 373-387. https://doi.org/10.1037/0022-3514.86.3.373

Chen, J. M., \& Ratliff, K. A. (2015). Implicit attitude generalization from Black to Black-White biracial group members. Social Psychological and Personality Science, 6(5), 544-550. https://doi.org/10.1177/1948550614567686

Corneille, O., \& Hütter, M. (2020). Implicit? What Do You Mean? A Comprehensive Review of the Delusive Implicitness Construct in Attitude Research. Personality and Social Psychology Review, 24(3), 212-232. https://doi.org/10.1177/1088868320911325

Dasgupta, N., McGhee, D. E., Greenwald, A. G., \& Banaji, M. R. (2000). Automatic preference for White Americans: Eliminating the familiarity explanation. Journal of Experimental Social Psychology, 36(3), 316-328. https://doi.org/10.1006/jesp.1999.1418

De Houwer, J. (2006). What are implicit measures and why are we using them. In The handbook of implicit cognition and addiction (pp. 11-28). Sage.

De Houwer, J., \& Moors, A. (2007). How to define and examine the implicitness of implicit measures. In Implicit measures of attitudes: Procedures and controversies (pp. 179-194). Guilford Press.

De Houwer, J., \& Moors, A. (2010). Implicit measures: Similarities and differences. In Handbook of implicit social cognition: Measurement, theory, and applications (pp. 176193). Guilford Press.

De Houwer, J., Teige-Mocigemba, S., Spruyt, A., \& Moors, A. (2009). Implicit measures: A normative analysis and review. Psychological Bulletin, 135(3), 347-368. https://doi.org/10.1037/a0014211 
DeSteno, D., Dasgupta, N., Bartlett, M. Y., \& Cajdric, A. (2004). Prejudice from thin air: The effect of emotion on automatic intergroup attitudes. Psychological Science, 15(5), 319324.

Devine, P. G. (1989). Stereotypes and prejudice: Their automatic and controlled components. Journal of Personality and Social Psychology, 56(1), 5-18. https://doi.org/10.1037/00223514.56.1.5

Devine, P. G., Monteith, M. J., Zuwerink, J. R., \& Elliot, A. J. (1991). Prejudice with and without compunction. Journal of Personality and Social Psychology, 60(6), 817-830. https://doi.org/10.1037/0022-3514.60.6.817

Devine, P. G., Plant, E. A., Amodio, D. M., Harmon-Jones, E., \& Vance, S. L. (2002). The regulation of explicit and implicit race bias: The role of motivations to respond without prejudice. Journal of Personality and Social Psychology, 82(5), 835-848. https://doi.org/10.1037//0022-3514.82.5.835

Dovidio, J. F., Kawakami, K., \& Gaertner, S. L. (2002). Implicit and Explicit Prejudice and Interracial Interaction. Journal of Personality and Social Psychology, 82(1), 62-68.

Dovidio, J. F., Kawakami, K., Johnson, C., Johnson, B., \& Howard, A. (1997). On the nature of prejudice: Automatic and controlled processes. Journal of Experimental Social Psychology, 33(5), 510-540. https://doi.org/10.1006/jesp.1997.1331

Egloff, B., \& Schmukle, S. C. (2002). Predictive validity of an implicit association test for assessing anxiety. Journal of Personality and Social Psychology, 83(6), 1441-1455. https://doi.org/10.1037/0022-3514.83.6.1441

Fazio, R. H. (2007). Attitudes as object-evaluation associations of varying strength. Social Cognition, 25(5), 603-637. https://doi.org/10.1521/soco.2007.25.5.603 
Fazio, R. H., Chen, J., McDonel, E. C., \& Sherman, S. J. (1982). Attitude accessibility, attitudebehavior consistency, and the strength of the object-evaluation association. Journal of Experimental Social Psychology, 18(4), 339-357. https://doi.org/10.1016/00221031(82)90058-0

Fazio, R. H., Jackson, J. R., Dunton, B. C., \& Williams, C. J. (1995). Variability in automatic activation as an unobtrusive measure of racial attitudes: A bona fide pipeline? Journal of Personality and Social Psychology, 69(6), 1013-1027. https://doi.org/10.1037/00223514.69.6.1013

Fazio, R. H., Sanbonmatsu, D. M., Powell, M. C., \& Kardes, F. R. (1986). On the automatic activation of attitudes. Journal of Personality and Social Psychology, 50(2), 229-238.

Fiske, S. T. (1998). Stereotyping, prejudice, and discrimination. In The handbook of social psychology, Vols. 1-2, 4th ed. (pp. 357-411). McGraw-Hill.

Fiske, S. T., \& Neuberg, S. L. (1990). A continuum of impression formation, from categorybased to individuating processes: Influences of information and motivation on attention and interpretation. In Advances in Experimental Social Psychology (Vol. 23, pp. 1-74). Elsevier. https://doi.org/10.1016/S0065-2601(08)60317-2

Forscher, P. S., Lai, C. K., Axt, J. R., Ebersole, C. R., Herman, M., Devine, P. G., \& Nosek, B. A. (2019). A meta-analysis of procedures to change implicit measures. Journal of Personality and Social Psychology, 117(3), 522-559. https://doi.org/10.1037/pspa0000160

Friese, M., Hofmann, W., \& Wänke, M. (2008). When impulses take over: Moderated predictive validity of explicit and implicit attitude measures in predicting food choice and consumption behaviour. British Journal of Social Psychology, 47(3), 397-419. 
Gawronski, B, \& De Houwer, J. (2014). Implicit measures in social and personality psychology. In Handbook of research methods in social and personality psychology (pp. 283-310). Cambridge University Press.

Gawronski, Bertram. (2019). Six lessons for a cogent science of implicit bias and Its criticism. Perspectives on Psychological Science, 14(4), 574-595. https://doi.org/10.1177/1745691619826015

Gawronski, Bertram, \& Brannon, S. M. (2019). Attitudes and the implicit-explicit dualism. The Handbook of Attitudes: Volume 1: Basic Principles, 158-196.

Gawronski, Bertram, De Houwer, J., \& Sherman, J. (in press). Twenty-Five Years of Research Using Implicit Measures. Social Cognition.

Gawronski, Bertram, \& Hahn, A. (2019). Implicit measures: Procedures, use, and interpretation. Measurement in Social Psychology., 29-55.

Gilbert, D. T. (1989). Thinking lightly about others: Automatic components of the social inference process. In Unintended thought. (pp. 189-211). Guilford Press.

Greenwald, A. G., McGhee, D. E., \& Schwartz, J. L. K. (1998). Measuring individual differences in implicit cognition: The implicit association test. Journal of Personality and Social Psychology, 74(6), 1464-1480. https://doi.org/10.1037/0022-3514.74.6.1464

Greenwald, A. G., \& Nosek, B. A. (2001). Health of the Implicit Association Test at age 3. Zeitschrift Für Experimentelle Psychologie, 48, 85-93.

Greenwald, A. G., Nosek, B. A., \& Banaji, M. R. (2003). Understanding and using the Implicit Association Test: I. An improved scoring algorithm. Journal of Personality and Social Psychology, 85(2), 197-216. https://doi.org/10.1037/0022-3514.85.2.197 
Hermans, D., Crombez, G., \& Eelen, P. (2000). Automatic attitude activation and efficiency: The fourth horseman of automaticity. Psychologica Belgica, 40(1), 3-22.

Hermans, D., De Houwer, J., \& Eelen, P. (2001). A time course analysis of the affective priming effect. Cognition \& Emotion, 15(2), 143-165.

Hofmann, W., Gawronski, B., Gschwendner, T., Le, H., \& Schmitt, M. (2005). A Meta-Analysis on the Correlation Between the Implicit Association Test and Explicit Self-Report Measures. Personality and Social Psychology Bulletin, 31(10), 1369-1385. https://doi.org/10.1177/0146167205275613

Hofmann, W., Gschwendner, T., Friese, M., Wiers, R. W., \& Schmitt, M. (2008). Working Memory Capacity and Self-Regulatory Behavior: Toward an Individual Differences Perspective on Behavior Determination by Automatic Versus Controlled Processes. Journal of Personality and Social Psychology, 95(4), 962-977.

Hofmann, W., Rauch, W., \& Gawronski, B. (2007). And deplete us not into temptation: Automatic attitudes, dietary restraint, and self-regulatory resources as determinants of eating behavior. Journal of Experimental Social Psychology, 43(3), 497-504.

Hommel, B. (2000). The prepared reflex: Automaticity and control in stimulus-response translation. In Control of cognitive processes: Attention and Performance, Vol. XVIII (pp. 247-273). MIT Press.

Ito, T. A., Friedman, N. P., Bartholow, B. D., Correll, J., Loersch, C., Altamirano, L. J., \& Miyake, A. (2015). Toward a comprehensive understanding of executive cognitive function in implicit racial bias. Journal of Personality and Social Psychology, 108(2), 187-218. https://doi.org/10.1037/a0038557 
Ito, T. A., \& Urland, G. R. (2003). Race and gender on the brain: Electrocortical measures of attention to the race and gender of multiply categorizable individuals. Journal of Personality and Social Psychology, 85(4), 616-626. https://doi.org/10.1037/00223514.85.4.616

Ito, T. A., \& Urland, G. R. (2005). The influence of processing objectives on the perception of faces: An ERP study of race and gender perception. Cognitive, Affective, \& Behavioral Neuroscience, 5(1), 21-36. https://doi.org/10.3758/CABN.5.1.21

Jeffreys, H. (1961). Theory of probability. (3rd ed.). Oxford University Press.

Jones, E. E., \& Nisbett, R. E. (1987). The actor and the observer: Divergent perceptions of the causes of behavior. In Attribution: Perceiving the causes of behavior. (pp. 79-94). Lawrence Erlbaum Associates, Inc.

Kim, D.-Y. (2003). Voluntary Controllability of the Implicit Association Test (IAT). Social Psychology Quarterly, 66(1), 83-96. JSTOR. https://doi.org/10.2307/3090143

Klauer, K. C., \& Teige-Mocigemba, S. (2007). Controllability and resource dependence in automatic evaluation. Journal of Experimental Social Psychology, 43(4), 648-655.

Klauer, K., Ronagel, C., \& Musch, J. (1997). List-Context Effects in Evaluative Priming. Journal of Experimental Psychology: Learning, Memory, and Cognition, 23(1), 246-255.

Kunda, Z., Davies, P. G., Adams, B. D., \& Spencer, S. J. (2002). The dynamic time course of stereotype activation: Activation, dissipation, and resurrection. Journal of Personality and Social Psychology, 82(3), 283-299. https://doi.org/10.1037/0022-3514.82.3.283

Kunda, Z., \& Sherman-Williams, B. (1993). Stereotypes and the construal of individuating information. Personality and Social Psychology Bulletin, 19(1), 90-99. https://doi.org/10.1177/0146167293191010 
Kunda, Z., \& Spencer, S. J. (2003). When do stereotypes come to mind and when do they color judgment? A goal-based theoretical framework for stereotype activation and application. Psychological Bulletin, 129(4), 522-544. https://doi.org/10.1037/0033-2909.129.4.522

Kurdi, B., Seitchik, A. E., Axt, J. R., Carroll, T. J., Karapetyan, A., Kaushik, N., Tomezsko, D., Greenwald, A. G., \& Banaji, M. R. (2019). Relationship between the Implicit Association Test and intergroup behavior: A meta-analysis. American Psychologist, 74(5), 569-586. https://doi.org/10.1037/amp0000364

Lai, C. K., Hoffman, K. M., \& Nosek, B. A. (2013). Reducing implicit prejudice. Social and Personality Psychology Compass, 7(5), 315-330. https://doi.org/10.1111/spc3.12023

Lai, C. K., Marini, M., Lehr, S. A., Cerruti, C., Shin, J.-E. L., Joy-Gaba, J. A., Ho, A. K., Teachman, B. A., Wojcik, S. P., Koleva, S. P., Frazier, R. S., Heiphetz, L., Chen, E. E., Turner, R. N., Haidt, J., Kesebir, S., Hawkins, C. B., Schaefer, H. S., Rubichi, S., ... Nosek, B. A. (2014). Reducing implicit racial preferences: I. A comparative investigation of 17 interventions. Journal of Experimental Psychology: General, 143(4), 1765-1785. https://doi.org/10.1037/a0036260

Lai, C. K., Skinner, A. L., Cooley, E., Murrar, S., Brauer, M., Devos, T., Calanchini, J., Xiao, Y. J., Pedram, C., Marshburn, C. K., Simon, S., Blanchar, J. C., Joy-Gaba, J. A., Conway, J., Redford, L., Klein, R. A., Roussos, G., Schellhaas, F. M. H., Burns, M., ... Nosek, B. A. (2016). Reducing implicit racial preferences: II. Intervention effectiveness across time. Journal of Experimental Psychology: General, 145(8), 1001-1016. https://doi.org/10.1037/xge0000179 
Lakens, D. (2013). Calculating and reporting effect sizes to facilitate cumulative science: A practical primer for t-tests and ANOVAs. Frontiers in Psychology, 4, 1-10. https://doi.org/10.3389/fpsyg.2013.00863

Logan, G. D. (1988). Toward an instance theory of automatization. Psychological Review, 95(4), 492-527. https://doi.org/10.1037/0033-295X.95.4.492

Lowery, B., Hardin, C., \& Sinclair, S. (2001). Social influence effects on automatic racial prejudice. Journal of Personality and Social Psychology, 81(5), 842-855.

Mackie, D. M., \& Smith, E. R. (1998). Intergroup relations: Insights from a theoretically integrative approach. Psychological Review, 105(3), 499-529. https://doi.org/10.1037/0033-295X.105.3.499

MacLeod, C., \& Dunbar, K. (1988). Training and Stroop-like interference: Evidence for a continuum of automaticity. Journal of Experimental Psychology. Learning, Memory, and Cognition, 14(1), 126-135.

Mann, T., \& Ferguson, M. (2015). Can we undo our first impressions? The role of reinterpretation in reversing implicit evaluations. Journal of Personality and Social Psychology, 108(6), 823-849.

McFarland, S. G., \& Crouch, Z. (2002). A Cognitive Skill Confound on the Implicit Association Test. Social Cognition, 20(6), 483-510. https://doi.org/10.1521/soco.20.6.483.22977

Mierke, J., \& Klauer, K. C. (2003). Method-Specific Variance in the Implicit Association Test. Journal of Personality and Social Psychology, 85(6), 1180-1192. https://doi.org/10.1037/0022-3514.85.6.1180 
Moran, T., Bar-Anan, Y., \& Nosek, B. A. (2017). The effect of the validity of co-occurrence on automatic and deliberate evaluations: Validity and automatic evaluations. European Journal of Social Psychology, 47(6), 708-723. https://doi.org/10.1002/ejsp.2266

Nosek, B. A. (2005). Moderators of the relationship between implicit and explicit evaluation. Journal of Experimental Psychology: General, 134(4), 565-584. https://doi.org/10.1037/0096-3445.134.4.565

Nosek, B. A. (2007). Implicit-explicit relations. Current Directions in Psychological Science, 16(2), 65-69. https://doi.org/10.1111/j.1467-8721.2007.00477.x

Nosek, B. A., Banaji, M., \& Greenwald, A. G. (2002). Harvesting implicit group attitudes and beliefs from a demonstration web site. Group Dynamics: Theory, Research, and Practice, 6(1), 101-115. https://doi.org/10.1037//1089-2699.6.1.101

Nosek, B. A., \& Banaji, M. R. (2002). (At least) two factors moderate the relationship between implicit and explicit attitudes. In Natura Automatyzmow (RK Ohme\&M. Jarymowicz, pp. 49-56). WIP PAN \& SWPS.

Nosek, B. A., Greenwald, A. G., \& Banaji, M. R. (2007). The Implicit Association Test at age 7: A methodological and conceptual review. In Frontiers of Social Psychology. Social psychology and the unconscious: The automaticity of higher mental processes. (pp. 265292). New York, NY, US: Psychology Press.

Nosek, B. A., Hawkins, C. B., \& Frazier, R. S. (2011). Implicit social cognition: From measures to mechanisms. Trends in Cognitive Sciences, 15(4), 152-159.

Nosek, B. A., Smyth, F. L., Hansen, J. J., Devos, T., Lindner, N. M., Ranganath, K. A., Smith, C. T., Olson, K. R., Chugh, D., Greenwald, A. G., \& Banaji, M. R. (2007). Pervasiveness 
and correlates of implicit attitudes and stereotypes. European Review of Social Psychology, 18(1), 36-88. https://doi.org/10.1080/10463280701489053

Olson, M. A., \& Fazio, R. H. (2001). Implicit attitude formation through classical conditioning. Psychological Science, 12(5), 413-417.

Olson, M. A., \& Fazio, R. H. (2004). Reducing the Influence of Extrapersonal Associations on the Implicit Association Test: Personalizing the IAT. Journal of Personality and Social Psychology, 86(5), 653-667. https://doi.org/10.1037/0022-3514.86.5.653

Ottaway, S. A., Hayden, D. C., \& Oakes, M. A. (2001). Implicit attitudes and racism: Effects of word familiarity and frequency on the implicit association test. Social Cognition, 19(2), 97-144. https://doi.org/10.1521/soco.19.2.97.20706

Payne, B. K. (2001). Prejudice and perception: The role of automatic and controlled processes in misperceiving a weapon. Journal of Personality and Social Psychology, 81(2), 181-192. https://doi.org/10.1037/0022-3514.81.2.181

Payne, B. K. (2005). Conceptualizing control in social cognition: How executive functioning modulates the expression of automatic stereotyping. Journal of Personality and Social Psychology, 89(4), 488-503. https://doi.org/10.1037/0022-3514.89.4.488

Petty, R., Tormala, Z., Briñol, P., \& Jarvis, W. (2006). Implicit ambivalence from attitude change: An exploration of the PAST model. Journal of Personality and Social Psychology, 90(1), 21-41.

Phelps, E. A., O’Connor, K. J., Cunningham, W. A., Funayama, E. S., Gatenby, J. C., Gore, J. C., \& Banaji, M. R. (2000). Performance on indirect measures of race evaluation predicts amygdala activation. Journal of Cognitive Neuroscience, 12(5), 729-738. https://doi.org/10.1162/089892900562552 
Plant, E. A., \& Devine, P. G. (1998). Internal and external motivation to respond without prejudice. Journal of Personality and Social Psychology, 75(3), 811-832. https://doi.org/10.1037/0022-3514.75.3.811

Powell, M. C., \& Fazio, R. H. (1984). Attitude accessibility as a function of repeated attitudinal expression. Personality and Social Psychology Bulletin, 10(1), 139-148.

Quinn, K. A., Mason, M. F., \& Macrae, C. N. (2009). Familiarity and person construal: Individuating knowledge moderates the automaticity of category activation. European Journal of Social Psychology, 39(5), 852-861.

Quinn, K. A., Mason, M. F., \& Macrae, C. N. (2010). When Arnold is “The Terminator", We No Longer See Him as a Man: The Temporal Determinants of Person Perception. Experimental Psychology, 57(1), 27-35. https://doi.org/10.1027/1618-3169/a000004

Ranganath, K. A., \& Nosek, B. A. (2008). Implicit attitude generalization occurs immediately; Explicit attitude generalization takes time. Psychological Science, 19(3), 249-254. https://doi.org/10.1111/j.1467-9280.2008.02076.x

Ratliff, K. A., \& Nosek, B. A. (2011). Negativity and outgroup biases in attitude formation and transfer. Personality and Social Psychology Bulletin, 37(12), 1692-1703. https://doi.org/10.1177/0146167211420168

Rosseel, Y. (2012). lavaan: An R package for Structural Equation Modeling. Journal of Statistical Software, 48(2). https://doi.org/10.18637/jss.v048.i02

Rothermund, K., \& Wentura, D. (2001). Figure-Ground Asymmetries in the Implicit Association Test (IAT). Experimental Psychology, 48(2), 94-106. https://doi.org/10.1026//09493946.48.2.94 
Rothermund, K., \& Wentura, D. (2004). Underlying Processes in the Implicit Association Test: Dissociating Salience From Associations. Journal of Experimental Psychology: General, 133(2), 139-165. https://doi.org/10.1037/0096-3445.133.2.139

Rouder, J. N., Morey, R. D., Speckman, P. L., \& Province, J. M. (2012). Default Bayes factors for ANOVA designs. Journal of Mathematical Psychology, 56(5), 356-374. https://doi.org/10.1016/j.jmp.2012.08.001

Rubinstein, R. S., Jussim, L., \& Stevens, S. T. (2018). Reliance on individuating information and stereotypes in implicit and explicit person perception. Journal of Experimental Social Psychology, 75, 54-70. https://doi.org/10.1016/j.jesp.2017.11.009

Rudman, L. A., \& Goodwin, S. A. (2004). Gender differences in automatic in-group bias: Why do women like women more than men like men? Journal of Personality and Social Psychology, 87(4), 494-509. https://doi.org/10.1037/0022-3514.87.4.494

Schmitz, F., Teige-Mocigemba, S., Voss, A., \& Klauer, K. C. (2013). When scoring algorithms matter: Effects of working memory load on different IAT scores. British Journal of Social Psychology, 52(1), 103-121.

Selker, R., Love, J., \& Dropmann, D. (2019). Jmv: The “jamovi” Analyses. R package version 0.9.6.1. https://CRAN.R-project.org/package=jmv

Smith, C. T., De Houwer, J., \& Nosek, B. A. (2013). Consider the source: Persuasion of implicit evaluations is moderated by source credibility. Personality and Social Psychology Bulletin, 39(2), 193-205.

Smith, E., \& Lerner, M. (1986). Development of Automatism of Social Judgments. Journal of Personality and Social Psychology, 50(2), 246-259. 
Spruyt, A., De Houwer, J., \& Hermans, D. (2009). Modulation of automatic semantic priming by feature-specific attention allocation. Journal of Memory and Language, 61(1), 37-54.

Spruyt, A., Hermans, D., De Houwer, J., Vandromme, H., \& Eelen, P. (2007). On the nature of the affective priming effect: Effects of stimulus onset asynchrony and congruency proportion in naming and evaluative categorization. Memory \& Cognition, 1(35), 95-106.

Spruyt, A., Lemaigre, V., Salhi, B., Van Gucht, D., Tibboel, H., Van Bockstaele, B., De Houwer, J., Van Meerbeeck, J., \& Nackaerts, K. (2015). Implicit attitudes towards smoking predict long-term relapse in abstinent smokers. Psychopharmacology, 232(14), 2551-2561.

Steffens, M. C. (2004). Is the Implicit Association Test Immune to Faking? Experimental Psychology, 51(3), 165-179. https://doi.org/10.1027/1618-3169.51.3.165

Teige-Mocigemba, S., \& Klauer, K. C. (2008). 'Automatic'evaluation? Strategic effects on affective priming. Journal of Experimental Social Psychology, 44(5), 1414-1417.

Uhlmann, E. L., Brescoll, V. L., \& Paluck, E. L. (2006). Are members of low status groups perceived as bad, or badly off? Egalitarian negative associations and automatic prejudice. Journal of Experimental Social Psychology, 42(4), 491-499. https://doi.org/10.1016/j.jesp.2004.10.003

Unkelbach, C., \& Fiedler, K. (2020). The challenge of diagnostic inferences from implicit measures: The case of non-evaluative influences in the evaluative priming paradigm. Social Cognition, 38(Supplement), s208-s222.

Van Dessel, P., De Houwer, J., Gast, A., Smith, C. T., \& De Schryver, M. (2016). Instructing implicit processes: When instructions to approach or avoid influence implicit but not explicit evaluation. Journal of Experimental Social Psychology, 63, 1-9. 
Van Dessel, P., Gawronski, B., Smith, C. T., \& De Houwer, J. (2017). Mechanisms underlying approach-avoidance instruction effects on implicit evaluation: Results of a preregistered adversarial collaboration. Journal of Experimental Social Psychology, 69, 23-32.

Vianello, M., \& Bar-Anan, Y. (In press). Can the Implicit Association Test measure automatic judgment? The validation continues. Perspectives on Psychological Science. https://osf.io/98tyj/

Volpert-Esmond, H. I., Scherer, L. D., \& Bartholow, B. D. (2019). Dissociating automatic associations: Comparing two implicit measurements of race bias. European Journal of Social Psychology, ejsp.2655. https://doi.org/10.1002/ejsp.2655

Westfall, J., \& Yarkoni, T. (2016). Statistically controlling for confounding constructs is harder than you yhink. PLOS ONE, 11(3), e0152719. https://doi.org/10.1371/journal.pone.0152719

Whitfield, M., \& Jordan, C. H. (2009). Mutual influence of implicit and explicit attitudes. Journal of Experimental Social Psychology, 45(4), 748-759. https://doi.org/10.1016/j.jesp.2009.04.006

Wiers, R. W., Beckers, L., Houben, K., \& Hofmann, W. (2009). A short fuse after alcohol: Implicit power associations predict aggressiveness after alcohol consumption in young heavy drinkers with limited executive control. Pharmacology Biochemistry and Behavior, 93(3), 300-305.

Wittenbrink, B., Judd, C., \& Park, B. (2001). Spontaneous prejudice in context: Variability in automatically activated attitudes. Journal of Personality and Social Psychology, 81(5), $815-827$. 